\title{
Synthesis and antiviral activity evaluation of new 4-thiazolidinones bearing an imidazo[2,1-b]thiazole moiety
}

\author{
Nuray Ulusoy Güzeldemirci 1,*, Erkan Pehlivan 1, Lieve Naesens ${ }^{2}$ \\ 1 Department of Pharmaceutical Chemistry, Faculty of Pharmacy, İstanbul University, Beyazit 34116 İstanbul, \\ Turkey \\ 2 Rega Institute for Medical Research, KU Leuven, B-3000 Leuven, Belgium \\ * Correspondence: nulusoy@istanbul.edu.tr (N.U.G.); Tel: +90 21244002 63; ORCID no: 0000-0002-4495-4282
}

Received: 27 August 2017 / Revised: 01 December 2017 / Accepted : 02 December 2017

\begin{abstract}
A series of new 4-thiazolidinone derivatives were synthesized and evaluated against diverse DNA- and RNA-viruses in mammalian cell cultures. Some of the compounds were found to exhibit moderate antiviral activity. 3Propyl-2-[((6-(4-chlorophenyl)imidazo[2,1-b]thiazol-3-yl)acetyl)hydrazono]-5-methyl-4-thiazolidinone 13, displayed modest yet consistent activity against three strains of influenza A virus, including the 2009 pandemic virus A/H1N1 Virginia/ATCC3/2009 (cytotoxicity >100 $\mu \mathrm{M}$ ). Compounds 6 and $\mathbf{1 1}$ displayed activity against vesicular stomatitis virus in HeLa cells (antiviral EC $\mathrm{E}_{50}$ values of 9 (cytotoxicity $100 \mu \mathrm{M}$ ) and $2 \mu \mathrm{M}$ (cytotoxicity $20 \mu \mathrm{M}$ ), respectively). Neither of the compounds was active against HIV.
\end{abstract}

KEYWORDS: Imidazo[2,1-b]thiazoles, 4-thiazolidinones, antiviral activity, synthesis.

\section{INTRODUCTION}

Despite significant advances in antiviral drug development during the past two decades, viral infections continue to cause serious morbidity and mortality world-wide. Diverse antiviral drugs are now available for the treatment of infections by HIV, herpes-, influenza, hepatitis B or hepatitis C viruses. Except for the broad antiviral agent ribavirin, there is no approved therapy for diverse emerging RNA viruses. In addition, new antiviral molecules are required to tackle the problems of drug toxicity and rapid development of drug resistance, which is particularly problematic for mutation-prone RNA viruses. Since virus replication occurs within host cells, and host cell metabolism and viral replication are tightly integrated, the development of compounds which selectively interfere with virus-specific process is one of the main challenges in antiviral drug design.

Imidazo[2,1-b]thiazole derivatives can have diverse pharmacological properties, such as antioxidant [1], cytotoxic [2], anti-infectious [3], antimicrobial [4], cystic fibrosis transmembrane conductance regulator (CFTR)-selective potentiators [5], 5-ht6 ligands [6], orexin receptor antagonists [7], selective cardiodepressant activity [8], inhibitors of insulin-like growth factor receptor and members of the epidermal growth factor family of receptor tyrosine kinases [9], anticancer [10,11] and hence occupy a prominent place in medicinal chemistry. There have been a few reports on imidazo[2,1-b]thiazole derivatives displaying antiviral activities [12-14]. Since our laboratory has built synthetic expertise in this chemical scaffold and related heterocyclic systems [15-20], we here synthesized new imidazo[2,1-b]thiazole derivatives and evaluated their potential antiviral properties in cell-based assays. We chose to combine the imidazo[2,1-b]thiazole skeleton with a 4thiazolidinone ring. Several researchers have incorporated this moiety into various biologically active compounds [21-32] (including antiviral molecules) (either as a substituent group or as a replacement for another cyclic system). For instance, several 2,3-diaryl-1,3-thiazolidin-4-ones have proved to be potent nonnucleoside HIV reverse transcriptase inhibitors (NNRTIs) [33, 34]. The HIV RT is a prime target for designing HIV inhibitors [35, 36].

We here report the synthesis, structural determination and antiviral evaluation of . 3-alkyl/aryl-2-[((6(phenyl/4-chlorophenyl)imidazo[2,1-b]thiazol-3-yl)acetyl)hydrazono]-5-nonsubstituted/methyl-4thiazolidinones.

How to cite this article: Ulusoy Güzeldemirci N, Pehlivan E, Naesens L. Synthesis and antiviral activity evaluation of new 4 thiazolidinones bearing an imidazo[2,1-b]thiazole moiety. Marmara Pharm J. 2018; 22 (2): 237-248. 


\section{RESULTS AND DISCUSSION}

The target compounds were prepared from 2-[6-(phenyl/4-chlorophenyl)imidazo[2,1-b]thiazol-3yl]acetohydrazides (C/D) [37], by a five step synthesis as shown in Figure 1. By heating ethyl (6-(phenyl/4chlorophenyl)imidazo[2,1-b]thiazol-3-yl)acetate hydrobromides (A/B) and hydrazine-hydrate in ethanol, 2[6-(phenyl/4-chlorophenyl)imidazo[2,1-b]thiazol-3-yl]acetohydrazides were obtained. Hydrazides and alkyl/aryl isothiocyanates were heated in ethanol to yield 4-alkyl/aryl-1-[(6-(phenyl/4chlorophenyl)imidazo[2,1-b]thiazol-3-yl)acetyl]-3-thiosemicarbazides E1-14 [38, 39]. The thiosemicarbazides were then reacted with ethyl a-bromoacetate/ethyl 2-bromopropionate in the presence of anhydrous sodium acetate in absolute ethanol to yield 3-alkyl/aryl-2-[((6-(phenyl/4-chlorophenyl)imidazo[2,1-b]thiazol-3yl)acetyl)hydrazono]-5-nonsubstituted/methyl-4-thiazolidinones 1-14.

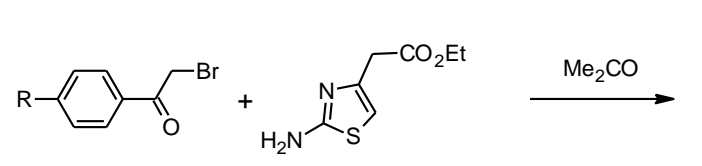<smiles>[R]OC(=O)Cc1csc(N)[n+]1CC(=O)c1ccc(Br)cc1</smiles>

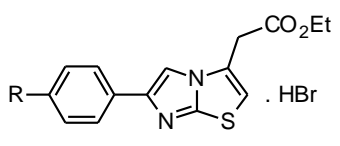

A, B<smiles></smiles>

Figure 1. The synthetic route for preparation of 1-14.

The yields and melting points of the compounds are given in Table 1. The structures of the obtained compounds were elucidated by spectral data.

Table 1. Yields and melting points (M.p.) of 4-thiazolidinone derivatives 1-14.

\begin{tabular}{cccccc}
\hline Compound & $\mathbf{R}$ & $\mathbf{R}_{\mathbf{1}}$ & $\mathbf{R}_{\mathbf{2}}$ & Yield (\%) & M.p. ('C) \\
\hline $\mathbf{1}$ & $\mathrm{H}$ & $\mathrm{C}_{6} \mathrm{H}_{5}$ & $\mathrm{H}$ & 87 & $272-273$ \\
$\mathbf{2}$ & $\mathrm{H}$ & $4-\mathrm{CH}_{3} \mathrm{C}_{6} \mathrm{H}_{4}$ & $\mathrm{H}$ & 96 & $266-267$ \\
$\mathbf{3}$ & $\mathrm{H}$ & $4-\mathrm{ClC}_{6} \mathrm{H}_{4}$ & $\mathrm{H}$ & 36 & $295-296$ \\
$\mathbf{4}$ & $\mathrm{C}$ & $\mathrm{CH}_{3}$ & 69 & $198-199$ \\
$\mathbf{5}$ & $\mathrm{H}$ & $\mathrm{C}_{3} \mathrm{H}_{7}$ & $\mathrm{CH}_{3}$ & 78 & $187-188$ \\
$\mathbf{6}$ & $\mathrm{H}$ & $\mathrm{CH}_{3}$ & 83 & $182-183$ \\
$\mathbf{7}$ & $\mathrm{H}$ & $\mathrm{CH}_{2}=\mathrm{CH}_{-} \mathrm{CH}_{2}$ & $\mathrm{CH}_{3}$ & 84 & $221-222$ \\
$\mathbf{8}$ & $\mathrm{C}$ & $\mathrm{C}_{6} \mathrm{H}_{5}$ & $\mathrm{CH}_{3}$ & 56 & $244-245$ \\
$\mathbf{9}$ & $\mathrm{H}$ & $4-\mathrm{CH}_{3} \mathrm{C}_{6} \mathrm{H}_{4}$ & $\mathrm{CH}_{3}$ & 40 & $204-205$ \\
$\mathbf{1 0}$ & $\mathrm{H}$ & $4-\mathrm{ClC}_{6} \mathrm{H}_{4}$ & $\mathrm{H}$ & 82 & $222-223$ \\
$\mathbf{1 1}$ & $\mathrm{Cl}$ & $\mathrm{C}_{3} \mathrm{H}_{7}$ & $\mathrm{CH}_{3}$ & 65 & $238-239$ \\
$\mathbf{1 2}$ & $\mathrm{Cl}$ & $\mathrm{CH}_{3}$ & $\mathrm{CH}_{3}$ & 41 & $234-235$ \\
$\mathbf{1 3}$ & $\mathrm{Cl}$ & $\mathrm{C}_{2} \mathrm{H}_{5}$ & $\mathrm{CH}_{3}$ & 66 & $241-242$ \\
$\mathbf{1 4}$ & $\mathrm{Cl}$ & $\mathrm{C}_{3} \mathrm{H}_{7}$ & $\mathrm{CH}_{3}$ & 69 & $253-254$ \\
\hline
\end{tabular}

4-Thiazolidinones 1-14 obtained from thiosemicarbazide gave absorption bands at 198-202 and 257-263 $\mathrm{nm}$ in UV spectra. In the IR spectra, some significant stretching bands due to $\mathrm{N}-\mathrm{H}$ and $\mathrm{C}=\mathrm{O}$ were observed at $3107-3257 \mathrm{~cm}^{-1}$ and $1635-1695 \mathrm{~cm}^{-1}$, respectively. A new strong band at $1695-1751 \mathrm{~cm}^{-1}$ (in some compounds two bonds [40] due to isomers) in the spectra of 1-14 provided firm support for ring closure [41]. ${ }^{1} \mathrm{H}-\mathrm{NMR}$ and ${ }^{13} \mathrm{C}-\mathrm{NMR}$ data were also in agreement with the formation of 4-thiazolidinone ring. $\mathrm{NH}$ signals of 1-14 appeared at $\delta$ 10.06-11.37 ppm. The exocyclic methylene protons of 4-6 and 10-13 displayed two singlets at $\delta$ 3.86-3.88 and $\delta$ 4.06-4.10 ppm or multiplets at $\delta$ 3.97-4.14 ppm for 1-3, 7-9 and 14 indicating the presence of two isomers in unequal proportions in $D M S O-\mathrm{d}_{6}$. This may be explained on the basis of the difference in the relative stability of the $E$ and $Z$ isomers formed due to the rotational restriction about the exocyclic $\mathrm{N}=\mathrm{C}$ bond 
at position 2 of the 4-thiazolidinone ring [38, 39]. In the ${ }^{1} \mathrm{H}-\mathrm{NMR}$ spectra of compounds 4-9, 11-14, $\mathrm{CH}-\mathrm{CH}_{3}$ protons appeared as a quartet $(1 \mathrm{H})$ at $\delta 4.37-4.53 \mathrm{ppm}$ and $\mathrm{CH}-\mathrm{CH}_{3}$ protons appeared as a doublet $(3 \mathrm{H})$ at $\delta$ 1.51-1.57 ppm which proved the closure of 4-thiazolidinone ring [42]. On the other hand, peak resonated at $\delta$ 43.24; 43.64, $\delta 157.16$ and $\delta 174.25 ; 174.75$ ppm in the ${ }^{13} \mathrm{C}-\mathrm{NMR}$ (APT), ${ }^{13} \mathrm{C}-\mathrm{NMR}$ (DEPT) and ${ }^{1} \mathrm{H}-{ }^{13} \mathrm{C}$ HSQC NMR spectrum of compound 3-ethyl-2-[((6-phenylimidazo[2,1-b]thiazol-3-yl)acetyl)hydrazono]-5-methyl-4thiazolidinone (4), assigned for $\mathrm{S}-\mathrm{CH}, \mathrm{C}=\mathrm{N}$ and $\mathrm{C}=\mathrm{O}$ moieties, confirms the carbon skeleton of 4thiazolidinone ring. These peaks were observed at $\delta 40.42 ; 40.48, \delta 151.82 ; 152.10$ and $\delta 172.47 ; 172.62 \mathrm{ppm}$ in the ${ }^{13} \mathrm{C}-\mathrm{NMR}$ (APT) spectrum of compounds 14. ESI (+) MS of the selected compounds 4 displayed protone molecular ion $[\mathrm{M}+1]^{+}$at $m / z 414$ which confirmed molecular weight.

The synthesized compounds were evaluated against a broad and diverse panel of RNA- and DNAviruses using cytopathic effect (CPE) reduction assays in appropriate cell culture models (see Experimental Section for the full list of viruses). As shown in Table 2, compound 6 had moderate activity against vesicular stomatitis virus (VSV) with an antiviral $\mathrm{EC}_{50}$ value of $9 \mu \mathrm{M}$ and selectivity index (SI: ratio of cytotoxic to antiviral concentration) of 11 . Compound $\mathbf{1 1}$ displayed an antiviral $\mathrm{EC}_{50}$ value of $2 \mu \mathrm{M}$ against VSV as well as respiratory syncytial virus (RSV), with a SI of 10 . For 14, anti-RSV activity was 5-fold lower but the SI was again 10. These three molecules (i.e., 6, 11 and 14) all have a methyl substituent at position $R_{2}$. Evaluation of the compounds against influenza virus (Table 3) revealed that some compounds displayed weak activity as visible by CPE or MTS assay. Compound 13 (which again carries a methyl at $R_{2}$ ) was the only one in the series with equal activity in the CPE and MTS assays, and its activity was consistent for three different strains of influenza A virus belonging to two subtypes (H1N1 and $\mathrm{H} 3 \mathrm{~N} 2$ ). However, its $\mathrm{EC}_{50}$ values were rather high (in the range of $60 \mu \mathrm{M}$ ). Finally, compound 7 displayed weak activity against adenovirus $\left(\mathrm{EC}_{50}: 42 \mu \mathrm{M}\right.$; data not shown), but not against any other DNA-virus tested. Neither of the synthesized compounds was found active against HIV-1 or -2 . In combination, these antiviral data suggested that the 5 -methylsubstituted thiazolidinone derivatives were more active than their nonsubstituted counterparts.

Table 2. Antiviral activity and cytotoxicity of compounds 1-14 in HeLa cells.

\begin{tabular}{|c|c|c|c|c|}
\hline \multirow[t]{2}{*}{ Compound } & \multirow{2}{*}{$\begin{array}{l}\text { Cytotoxicity } \\
\text { MCC }^{a}(\mu M)\end{array}$} & \multicolumn{3}{|c|}{ Antiviral $\mathrm{EC}_{50} \mathrm{~b}(\mu \mathrm{M})$} \\
\hline & & $\begin{array}{c}\text { Vesicular stomatitis } \\
\text { virus }\end{array}$ & Coxsackie B4 virus & $\begin{array}{c}\text { Respiratory syncytial } \\
\text { virus }\end{array}$ \\
\hline 1 & $>100$ & $>100$ & $>100$ & $>100$ \\
\hline 2 & $>100$ & $>100$ & $>100$ & $>100$ \\
\hline 3 & $\geq 20$ & $>100$ & $>100$ & $>100$ \\
\hline 4 & 100 & $>100$ & $>100$ & $>100$ \\
\hline 5 & $\geq 20$ & $>100$ & $>100$ & $>100$ \\
\hline 6 & 100 & 9 & $>100$ & $>100$ \\
\hline 7 & $\geq 100$ & $>100$ & $>100$ & $>100$ \\
\hline 8 & ND & ND & ND & ND \\
\hline 9 & $\geq 20$ & $>100$ & $>100$ & $>100$ \\
\hline 10 & $>100$ & $>100$ & $>100$ & $>100$ \\
\hline 11 & 20 & 2 & $>100$ & $\geq 2$ \\
\hline 12 & 100 & $>100$ & $>100$ & $>100$ \\
\hline 13 & $\geq 20$ & $>100$ & $>100$ & $>100$ \\
\hline 14 & 100 & $>100$ & $>100$ & 10 \\
\hline DS-5000c & $>100$ & 3.5 & 79 & 4 \\
\hline Ribavirin & $>250$ & 16 & 112 & 16 \\
\hline
\end{tabular}

aMinimum cytotoxic concentration, i.e. compound concentration that causes minimal alterations in cell morphology as assessed by microscopy. ${ }^{b} \mathrm{EC}_{50}: 50 \%$ effective concentration or concentration producing $50 \%$ inhibition of virus-induced cytopathic effect, as determined by visual scoring of the cytopathic effect (CPE). cDS-5000: dextran sulfate MW 5000; these data are expressed in $\mu \mathrm{g} / \mathrm{ml}$. ND, not done.

The diverse virus testing panel allowed to estimate the cytotoxicity of the compounds in various mammalian cell lines (Table 4). Most were not cytotoxic at $100 \mu \mathrm{M}$, the highest concentration tested. Compound 9 was the only compound showing cytotoxicity in all cell lines examined; depending on the cell line, its cytotoxic concentrations varied between 4 and $100 \mu \mathrm{M}$. 
Table 3. Anti-influenza virus activity and cytotoxicity of compounds 1-14 in MDCKa cells.

\begin{tabular}{|c|c|c|c|c|c|c|c|c|c|c|}
\hline \multirow[t]{3}{*}{ Compound } & \multirow{2}{*}{\multicolumn{2}{|c|}{ Cytotoxicity $(\mu \mathrm{M})$}} & \multicolumn{8}{|c|}{ Antiviral $\mathrm{EC}_{50} \mathrm{~b}(\mu \mathrm{M})$} \\
\hline & & & \multicolumn{2}{|c|}{$\begin{array}{c}\text { Influenza A/H1N1 } \\
(\mathrm{A} / \mathrm{PR} / 8 / 34)\end{array}$} & \multicolumn{2}{|c|}{$\begin{array}{c}\text { Influenza A/H1N1 } \\
\text { (A/Virginia/ } \\
\text { ATCC3/2009) }\end{array}$} & \multicolumn{2}{|c|}{$\begin{array}{c}\text { Influenza A/H3N2 } \\
(\mathrm{A} / \mathrm{HK} / 7 / 87)\end{array}$} & \multicolumn{2}{|c|}{$\begin{array}{c}\text { Influenza B } \\
(\mathrm{B} / \mathrm{HK} / 5 / 72)\end{array}$} \\
\hline & $\mathrm{CC}_{50^{\mathrm{c}}}$ & MCCd & CPE & MTS & $\mathrm{CPE}$ & MTS & CPE & MTS & $\mathrm{CPE}$ & MTS \\
\hline 1 & $>100$ & $>100$ & $>100$ & $>100$ & $>100$ & $>100$ & $>100$ & $>100$ & $>100$ & $>100$ \\
\hline 2 & $>100$ & $\geq 100$ & $>100$ & $>100$ & $>100$ & $>100$ & $>100$ & 24 & $>100$ & $>100$ \\
\hline 3 & $>100$ & $>100$ & $>100$ & $>100$ & $>100$ & 32 & $>100$ & $>100$ & $>100$ & $>100$ \\
\hline 4 & $>100$ & $\geq 100$ & 20 & $<0.80$ & $>100$ & $>100$ & $>100$ & $>100$ & $>100$ & $>100$ \\
\hline 5 & $>100$ & $\geq 100$ & $>100$ & $>100$ & $>100$ & $>100$ & $>100$ & $>100$ & $>100$ & $>100$ \\
\hline 6 & $>100$ & $\geq 100$ & $>100$ & $>100$ & $>100$ & $>100$ & $>100$ & $>100$ & $>100$ & $>100$ \\
\hline 7 & $\geq 83$ & 100 & $>100$ & $>100$ & $>100$ & $>100$ & $>100$ & 6.5 & $>100$ & $>100$ \\
\hline 8 & ND & ND & ND & ND & ND & ND & ND & ND & ND & ND \\
\hline 9 & 4.8 & 4.0 & $>100$ & $>100$ & $>100$ & $>100$ & $>100$ & $>100$ & $>100$ & $>100$ \\
\hline 10 & $>100$ & $\geq 100$ & $>100$ & $>100$ & $>100$ & $>100$ & $>100$ & 50 & $>100$ & $>100$ \\
\hline 11 & 74 & 73 & $>100$ & $>100$ & $>100$ & $>100$ & $>100$ & $>100$ & $>100$ & $>100$ \\
\hline 12 & $>100$ & $>100$ & $>100$ & $>100$ & $>100$ & $>100$ & $>100$ & $>100$ & $>100$ & $>100$ \\
\hline 13 & $>100$ & $>100$ & $>100$ & 65 & 79 & 56 & $>100$ & 69 & $>100$ & $>100$ \\
\hline 14 & 11 & $\geq 4.0$ & $>100$ & $>100$ & $>100$ & $>100$ & $>100$ & $>100$ & $>100$ & $>100$ \\
\hline Zanamivir & $>100$ & $>100$ & 0.36 & 0.77 & 20 & 5.6 & 5.8 & 4.8 & 45 & 26 \\
\hline Ribavirin & $>100$ & $\geq 20$ & 7.6 & 9.4 & 8.9 & 12 & 8.9 & 8.7 & 12 & 8.7 \\
\hline Amantadine & $>500$ & $\geq 500$ & 197 & 101 & $>500$ & $>500$ & 0.56 & 0.64 & $>500$ & $>500$ \\
\hline Rimantadine & 336 & 500 & 20 & 7.3 & $>500$ & $>500$ & 0.062 & 0.057 & $>500$ & $>500$ \\
\hline
\end{tabular}

aMDCK: Madin-Darby canine kidney cells. ${ }^{\mathrm{b}} \mathrm{EC}_{50}$ : $50 \%$ effective concentration or concentration producing $50 \%$ inhibition of virusinduced cytopathic effect, as determined by visual scoring of the cytopathic effect (CPE) or by measuring cell viability with the colorimetric formazan-based MTS assay. c50\% Cytotoxic concentration, as determined by measuring cell viability with the colorimetric formazan based MTS assay. ${ }^{d}$ Minimum cytotoxic concentration, i.e. compound concentration that causes minimal alterations in cell morphology as assessed by microscopy. ND, not done.

\section{CONCLUSION}

In conclusion, we synthesized a series of imidazo[2,1-b]thiazoles bearing 4-thiazolidinone moieties. The new compounds were characterized by UV, IR, NMR spectra, mass spectra as well as elemental analyses. Antiviral activity testing revealed that some of the compounds exhibited antiviral activity against diverse RNA viruses (cytotoxic concentrations range of $>100-20 \mu \mathrm{M}$ ). In order to improve the antiviral potency, chemical synthesis of additional thiazolidinone fused imidazo[2,1-b]thiazoles is warranted.

\section{MATERIALS AND METHODS}

\subsection{Chemistry}

Melting points were determined by using a Büchi B-540 melting point apparatus in open capillary tubes and are uncorrected. Elemental analyses were performed on a Thermo Finnigan Flash EA 1112 elemental analyzer. IR spectra were recorded on $\mathrm{KBr}$ discs, using a Shimadzu IR Affinity-1 FT-IR spectrophotometer. ${ }^{1} \mathrm{H}-\mathrm{NMR},{ }^{13} \mathrm{C}-\mathrm{NMR}$ (APT), ${ }^{13} \mathrm{C}-\mathrm{NMR}$ (DEPT) and HSQC $\left({ }^{1} \mathrm{H}-{ }^{13} \mathrm{C}\right)$ spectra were measured on a Varian UNITY INOVA $(500 \mathrm{MHz})$ spectrometer using $D M S O-\mathrm{d}_{6}$. Mass spectra were recorded on a Thermo Finnigan LCQ Advantage Max instrument. The starting materials were either commercially available or synthesized according to the references cited. 
Table 4. Cytotoxicity of compounds 1-14 in diverse mammalian cell linesa.

\begin{tabular}{|c|c|c|c|c|c|c|}
\hline \multirow[t]{2}{*}{ Compound } & \multicolumn{4}{|c|}{$\mathbf{M C C}^{\mathbf{b}}(\mu \mathrm{M})$} & \multicolumn{2}{|c|}{$\mathrm{CC}_{50^{c}}(\mu \mathrm{M})$} \\
\hline & HEL & HeLa & Vero & MDCK & CRFK & MT4 \\
\hline 1 & $>100$ & $>100$ & $>100$ & $>100$ & $>100$ & $>125$ \\
\hline 2 & 100 & $>100$ & $>100$ & $\geq 100$ & $>100$ & 73 \\
\hline 3 & $>100$ & $\geq 20$ & $\geq 20$ & $>100$ & $>100$ & $>125$ \\
\hline 4 & $>100$ & 100 & 100 & $\geq 100$ & $>100$ & 50 \\
\hline 5 & $>100$ & $\geq 20$ & 100 & $\geq 100$ & $>100$ & 30 \\
\hline 6 & $>100$ & 100 & $>100$ & $\geq 100$ & $>100$ & 39 \\
\hline 7 & $>100$ & $\geq 100$ & 100 & 100 & $>100$ & 62 \\
\hline 8 & ND & ND & ND & ND & ND & ND \\
\hline 9 & 100 & $\geq 20$ & 100 & 4.0 & 15 & 34 \\
\hline 10 & $>100$ & $>100$ & $\geq 20$ & $\geq 100$ & $>100$ & 52 \\
\hline 11 & $>100$ & 20 & $\geq 100$ & 73 & $>100$ & 24 \\
\hline 12 & $>100$ & 100 & $>100$ & $>100$ & $>100$ & $>125$ \\
\hline 13 & 100 & $\geq 20$ & $\geq 20$ & $>100$ & $>100$ & $>125$ \\
\hline 14 & $>100$ & 100 & $>100$ & $\geq 4.0$ & $>100$ & 58 \\
\hline DS-5000d & ND & $>100$ & $>100$ & ND & ND & ND \\
\hline Ribavirin & $>250$ & $>250$ & $>250$ & 100 & ND & ND \\
\hline Ganciclovir & $>100$ & ND & ND & ND & $>100$ & ND \\
\hline Azidothymidine & ND & ND & ND & ND & ND & $>25$ \\
\hline
\end{tabular}

aHEL: human embryonic lung fibroblast cells; HeLa: human cervix carcinoma cells; Vero: African green monkey kidney cells; MDCK: Madin-Darby canine kidney cells; CRFK: Crandell-Rees feline kidney cells; MT4: human T-lymphoblast cells.

bMCC: minimum inhibitory concentration, or compound concentration causing minimal changes in cell morphology, as assessed by microscopy. ${ }^{c} C_{50}: 50 \%$ cytotoxic concentration, assessed by the spectroscopic MTS cell viability assay.

dDS-5000: dextran sulfate with MW 5000; these data are expressed in $\mu \mathrm{g} / \mathrm{ml}$. ND, not done.

\subsubsection{Preparation of ethyl (6-(phenyl/4-chlorophenyl)imidazo[2,1-b] thiazol-3-yl)acetate hydrobromides $(A, B)$}

These compounds were obtained according to the procedure described by Robert et al [43].

\subsubsection{Preparation of 2-[6-(phenyl/4-chlorophenyl)imidazo[2,1-b]thiazol-3-yl]acetohydrazides $(C, D)$}

These compounds were prepared according to the procedure described by Kuhmstedt et al [44].

\subsubsection{Preparation of 4-alkyl/aryl-1-[(6-(phenyl/4-chlorophenyl)imidazo[2,1-b]thiazol-3-yl)acetyl]-3-thiosemicarbazides} (E1-14)

To a solution of 2-[6-(phenyl/4-chlorophenyl)imidazo[2,1-b]thiazole-3-yl]acetohydrazides (A) $(0.005$ $\mathrm{mol})$ in ethanol $(30 \mathrm{~mL})$ were added the appropriate isothiocyanate $(0.005 \mathrm{~mol})$. The resulting mixture was heated under reflux for $3 \mathrm{~h}$. After cooling, the precipitate was separated and purified by washing with hot ethanol.

4.1.4. General procedure for preparation of 3-alkyl/aryl-2-[((6-(phenyl/4-chlorophenyl)imidazo[2,1-b]thiazol-3yl)acetyl)hydrazono]-5-nonsubstituted/methyl-4-thiazolidinones derivatives (1-14)

To a suspension of 4-alkyl/aryl-1-[(6-(phenyl/4-chlorophenyl)imidazo[2,1-b]thiazol-3-yl)acetyl]-3thiosemicarbazides (E1-14) $(0.005 \mathrm{~mol})$ in absolute ethanol $(30 \mathrm{~mL})$ were added anhydrous sodium acetate $(0.02 \mathrm{~mol})$ and ethyl bromoacetate/ethyl 2-bromopropionate $(0.005 \mathrm{~mol})$. The reaction mixture was refluxed for $5 \mathrm{~h}$ (for 1-4, 6-10 and 14) or $20 \mathrm{~h}$ (for 5, 11-13), then cooled, diluted with water and allowed to stand overnight. The crystals were filtered, dried and purified by crystallization from ethanol or ethanol/water.

\section{3-Phenyl-2-[((6-phenylimidazo[2,1-b]thiazol-3-yl)acetyl)hydrazono]-4-thiazolidinone (1)}

UV $\lambda_{\max }(\mathrm{nm}): 200$ (ع 134124), 259 (ع 38398). IR $\mathrm{v}_{\max }\left(\mathrm{cm}^{-1}\right): 3244,3116$ (N-H stretching), 3024 (aromatic C$\mathrm{H}$ stretching), 2964, 2908 (C-H stretching), 1739 (thiazolidinone C=O stretching), 1678, 1643 (amide I C=O stretching), 1593, 1523 ( $\mathrm{C}=\mathrm{N}, \mathrm{C}=\mathrm{C}$ stretching and amide II, N-H bending vibrations combined with C-N stretching), 1471, 1384 (C-H bending), 1276 (amide III, N-H bending vibrations combined with C-N stretching), 707 (aromatic substitution bending). ${ }^{1} \mathrm{H}-\mathrm{NMR} \delta(\mathrm{ppm}): 4.03-4.13\left(\mathrm{~m}, 2 \mathrm{H}, \mathrm{CH}_{2} \mathrm{CO}\right), 4.20(\mathrm{~s}, 2 \mathrm{H}$, thiazolidinone 5- $\left.\mathrm{CH}_{2}\right), 6.91\left(\mathrm{~d}, 2 \mathrm{H}, \mathrm{J}=7.32 \mathrm{~Hz}\right.$, thiazolidinone 3-Ph $\left.\mathrm{C}_{2,6}-\mathrm{H}\right), 7.14\left(\mathrm{~s}, 1 \mathrm{H}\right.$, imidazothiazole $\left.\mathrm{C}_{2}-\mathrm{H}\right)$, 7.16-7.27 $(\mathrm{m}$, $4 \mathrm{H}$, thiazolidinone 3-Ph $\mathrm{C}_{3,4,5}-\mathrm{H}$ ve $\left.\mathrm{Ph} \mathrm{C}_{4}-\mathrm{H}\right), 7.35$ and $7.37\left(2 \mathrm{~d}, 2 \mathrm{H}, J=8.30 ; 7.32 \mathrm{~Hz}, \mathrm{Ph} \mathrm{C}_{3,5}-\mathrm{H}\right), 7.65(\mathrm{~d}, 2 \mathrm{H}, J=$ 
$\left.8.30 \mathrm{~Hz}, \mathrm{Ph} \mathrm{C}_{2,6}-\mathrm{H}\right), 8.09$ (s, $1 \mathrm{H}$, imidazothiazole $\left.\mathrm{C}_{5}-\mathrm{H}\right), 11.33(\mathrm{~s}, 1 \mathrm{H}, \mathrm{CONH})$. Anal. Calcd. for $\mathrm{C}_{22} \mathrm{H}_{17} \mathrm{~N}_{5} \mathrm{O}_{2} \mathrm{~S}_{2}: \mathrm{C}$, 59.04; H, 3.83; N, 15.65; Found: C, 58.99; H, 3.48; N, 15.42.

3-(4-Methylphenyl)-2-[((6-phenylimidazo[2,1-b]thiazol-3-yl)acetyl)hydrazono]-4-thiazolidinone (2)

UV $\lambda_{\max }(\mathrm{nm}): 199$ (ع 138954), 260 (ع 34865). IR $\mathrm{V}_{\max }\left(\mathrm{cm}^{-1}\right): 3257,3116$ (N-H stretching), 3026 (aromatic C$\mathrm{H}$ stretching), 2953, 2904 (C-H stretching), 1735 (thiazolidinone $\mathrm{C}=\mathrm{O}$ stretching), 1681, 1643 (amide I C=O stretching), 1602, $1521(\mathrm{C}=\mathrm{N}, \mathrm{C}=\mathrm{C}$ stretching and amide II, N-H bending vibrations combined with C-N stretching), 1471, 1379 (C-H bending), 1267 (amide III, N-H bending vibrations combined with C-N stretching), 823, 705 (aromatic substitution bending). ${ }^{1} \mathrm{H}-\mathrm{NMR} \delta(\mathrm{ppm}): 2.29$ (s, 3H, thiazolidinone 3-Ph 4- $\mathrm{CH}_{3}$ ), 4.01-4.11 $\left(\mathrm{m}, 2 \mathrm{H}, \mathrm{CH}_{2} \mathrm{CO}\right), 4.17\left(\mathrm{~s}, 2 \mathrm{H}\right.$, thiazolidinone $\left.5-\mathrm{CH}_{2}\right), 6.79\left(\mathrm{~d}, 2 \mathrm{H}, \mathrm{J}=8.30 \mathrm{~Hz}\right.$, thiazolidinone 3-Ph $\left.\mathrm{C}_{3,5} \mathrm{-H}\right), 7.13$ $\left(\mathrm{s}, 1 \mathrm{H}\right.$, imidazothiazole $\left.\mathrm{C}_{2}-\mathrm{H}\right), 7.15\left(\mathrm{~s}, 1 \mathrm{H}, \mathrm{Ph} \mathrm{C}_{4}-\mathrm{H}\right), 7.19-7.26\left(\mathrm{~m}, 4 \mathrm{H}, \mathrm{Ph} \mathrm{C}_{3,5}-\mathrm{H}\right.$ ve tiy. 3-Ph $\left.\mathrm{C}_{2,6}-\mathrm{H}\right), 7.65(\mathrm{~d}$, $\left.2 \mathrm{H}, \mathrm{J}=8.30 \mathrm{~Hz}, \mathrm{Ph} \mathrm{C}_{2,6}-\mathrm{H}\right), 8.10\left(\mathrm{~s}, 1 \mathrm{H}\right.$, imidazothiazole $\left.\mathrm{C}_{5}-\mathrm{H}\right)$, $\mathrm{NH}$ proton not observed. Anal. Calcd. for $\mathrm{C}_{23} \mathrm{H}_{19} \mathrm{~N}_{5} \mathrm{O}_{2} \mathrm{~S}_{2}$ : C, 59.85; H, 4.15; N, 15.17; Found: C, 59.30; H, 3.74; N, 14.82 .

\section{3-(4-Chlorophenyl)-2-[((6-phenylimidazo[2,1-b]thiazol-3-yl)acetyl)hydrazono]-4-thiazolidinone (3)}

UV $\lambda_{\max }(\mathrm{nm}): 201$ (ع 145345), 263 (ع 30605). IR $\mathrm{V}_{\max }\left(\mathrm{cm}^{-1}\right):$ 3207, 3124 (N-H stretching), 3010 (aromatic C$\mathrm{H}$ stretching), 2954, 2900 (C-H stretching), 1732 (thiazolidinone $\mathrm{C}=\mathrm{O}$ stretching), 1674, 1651 (amide I C=O stretching), 1589, 1525 ( $\mathrm{C}=\mathrm{N}, \mathrm{C}=\mathrm{C}$ stretching and amide II, N-H bending vibrations combined with C-N stretching), 1471, 1381 (C-H bending), 1274 (amide III, N-H bending vibrations combined with C-N stretching), 1089 (aromatic C-Cl stretching), 829, 704 (aromatic substitution bending). ${ }^{1} \mathrm{H}-\mathrm{NMR} \delta(\mathrm{ppm}): 4.06-4.10(\mathrm{~m}, 2 \mathrm{H}$, $\left.\mathrm{CH}_{2} \mathrm{CO}\right), 4.22\left(\mathrm{~s}, 2 \mathrm{H}\right.$, thiazolidinone 5- $\left.\mathrm{CH}_{2}\right), 6.91\left(\mathrm{~d}, 2 \mathrm{H}, \mathrm{J}=8.30 \mathrm{~Hz}\right.$, thiazolidinone 3-Ph $\left.\mathrm{C}_{3,5}-\mathrm{H}\right), 7.13(\mathrm{~s}, 1 \mathrm{H}$, imidazothiazole $\left.\mathrm{C}_{2}-\mathrm{H}\right)$, 7.19-7.27 $\left(\mathrm{m}, 3 \mathrm{H}\right.$, thiazolidinone 3-Ph $\mathrm{C}_{2,6}-\mathrm{H}$ and $\left.\mathrm{Ph} \mathrm{C}_{4}-\mathrm{H}\right), 7.37-7.39(2 \mathrm{~d}, 2 \mathrm{H}, \mathrm{J}=8.30$; $\left.8.78 \mathrm{~Hz}, \mathrm{Ph} \mathrm{C}_{3,5}-\mathrm{H}\right), 7.63\left(\mathrm{~d}, 2 \mathrm{H}, \mathrm{J}=7.32 \mathrm{~Hz}, \mathrm{Ph} \mathrm{C}_{2,6}-\mathrm{H}\right), 8.07$ (s, 1H, imidazothiazole $\left.\mathrm{C}_{5}-\mathrm{H}\right), 11.34(\mathrm{~s}, 1 \mathrm{H}, \mathrm{CONH})$. Anal. Calcd. for $\mathrm{C}_{22} \mathrm{H}_{16} \mathrm{ClN}_{5} \mathrm{O}_{2} \mathrm{~S}_{2}$ : C, 54.82; $\mathrm{H}, 3.35 ; \mathrm{N}, 14.53$; Found: $\mathrm{C}, 54.27 ; \mathrm{H}, 3.06 ; \mathrm{N}, 14.26$.

\section{3-Ethyl-2-[((6-phenylimidazo[2,1-b]thiazol-3-yl)acetyl)hydrazono]-5-methyl-4-thiazolidinone (4)}

UV $\lambda_{\max }(\mathrm{nm}): 199$ ( $\varepsilon$ 128642), 258 (ع 59380). IR $\mathrm{v}_{\max }\left(\mathrm{cm}^{-1}\right): 3182,3151$ (N-H stretching), 3103 (aromatic C-H stretching), 2976, 2933 (C-H stretching), 1716 (thiazolidinone C=O stretching), 1695, 1672 (amide I C=O stretching), 1618, $1556(\mathrm{C}=\mathrm{N}, \mathrm{C}=\mathrm{C}$ stretching and amide II, N-H bending vibrations combined with C-N stretching), 1438, 1390 (C-H bending), 1219 (amide III, N-H bending vibrations combined with C-N stretching), 705 (aromatic substitution bending). ${ }^{1} \mathrm{H}-\mathrm{NMR} \delta(\mathrm{ppm}): 1.12$ and $1.22(2 \mathrm{t}, 3 \mathrm{H}, \mathrm{J}=7.32 ; 7.32 \mathrm{~Hz}$, thiazolidinone $\left.\mathrm{N}-\mathrm{CH}_{2}-\mathrm{CH}_{3}\right), 1.52\left(\mathrm{~d}, 3 \mathrm{H}, \mathrm{J}=7.32 \mathrm{~Hz}\right.$, thiazolidinone $\left.5-\mathrm{CHCH}_{3}\right), 3.68$ and $4.06(2 \mathrm{q}, 2 \mathrm{H}, \mathrm{J}=7.32 ; 7.32 \mathrm{~Hz}$, thiazolidinone $\left.\mathrm{N}_{-} \mathrm{CH}_{2}\right), 3.88$ and $4.10\left(2 \mathrm{~s}, 2 \mathrm{H}, \mathrm{CH}_{2} \mathrm{CO}\right), 4.38\left(\mathrm{q}, 1 \mathrm{H}, \mathrm{J}=7.32 \mathrm{~Hz}\right.$, thiazolidinone 5- $\left.\mathrm{CHCH}_{3}\right), 7.05$ and 7.18 $\left(2 \mathrm{~s}, 1 \mathrm{H}\right.$, imidazothiazole $\left.\mathrm{C}_{2}-\mathrm{H}\right), 7.23-7.27\left(\mathrm{~m}, 1 \mathrm{H}, \mathrm{Ph} \mathrm{C}_{4}-\mathrm{H}\right), 7.38$ and $7.41(2 \mathrm{~d}, 2 \mathrm{H}, \mathrm{J}=7.32 ; 7.32 \mathrm{~Hz}, \mathrm{Ph}$ $\left.\mathrm{C}_{3,5}-\mathrm{H}\right), 7.81$ and $7.82\left(2 \mathrm{~d}, 2 \mathrm{H}, \mathrm{J}=7.32 ; 7.32 \mathrm{~Hz}, \mathrm{Ph} \mathrm{C}_{2,6}-\mathrm{H}\right), 8.18$ and $8.20\left(2 \mathrm{~s}, 1 \mathrm{H}\right.$, imidazothiazole $\left.\mathrm{C}_{5}-\mathrm{H}\right), 10.65$ $(\mathrm{s}, 1 \mathrm{H}, \mathrm{CONH}) .{ }^{1} \mathrm{H}-\mathrm{NMR}\left(\mathrm{D}_{2} \mathrm{O}\right) \delta(\mathrm{ppm}): 1.07$ and $1.17\left(2 \mathrm{t}, 3 \mathrm{H}, \mathrm{J}=7.32 ; 6.84 \mathrm{~Hz}\right.$, thiazolidinone $\left.\mathrm{N}-\mathrm{CH}_{2}-\mathrm{CH}_{3}\right)$, $1.47\left(\mathrm{~d}, 3 \mathrm{H}, \mathrm{J}=7.32 \mathrm{~Hz}\right.$, thiazolidinone $\left.5-\mathrm{CH}-\mathrm{CH}_{3}\right), 3.66$ and $4.03(2 \mathrm{q}, 2 \mathrm{H}, \mathrm{J}=7.32 ; 7.32 \mathrm{~Hz}$, thiazolidinone N$\left.\mathrm{CH}_{2}\right), 3.94(\mathrm{HDO}), 3.85$ and $4.05\left(2 \mathrm{~s}, 2 \mathrm{H}, \mathrm{CH}_{2} \mathrm{CO}\right), 4.29\left(\mathrm{q} 1 \mathrm{H}, \mathrm{J}=7.32 \mathrm{~Hz}\right.$, thiazolidinone 5- $\left.\mathrm{CHCH}_{3}\right), 7.00$ and $7.11\left(2 \mathrm{~s}, 1 \mathrm{H}\right.$, imidazothiazole $\left.\mathrm{C}_{2}-\mathrm{H}\right), 7.24-7.26\left(\mathrm{~m}, 1 \mathrm{H}, \mathrm{Ph} \mathrm{C}_{4}-\mathrm{H}\right), 7.35$ ve $7.38\left(2 \mathrm{~d}, 2 \mathrm{H}, \mathrm{J}=6.84 ; 7.32 \mathrm{~Hz}, \mathrm{Ph} \mathrm{C}_{3,5-}\right.$ $\mathrm{H}), 7.74$ and $7.76\left(2 \mathrm{~d}, 2 \mathrm{H}, \mathrm{J}=9.27 ; 7.81 \mathrm{~Hz}, \mathrm{Ph} \mathrm{C}_{2,6}-\mathrm{H}\right), 8.06$ and $8.12\left(2 \mathrm{~s}, 1 \mathrm{H}\right.$, imidazothiazole $\left.\mathrm{C}_{5}-\mathrm{H}\right) .{ }^{13} \mathrm{C}-\mathrm{NMR}$ (APT) (125 MHz $\delta$ (ppm): 12.81; 13.91 (thiazolidinone $\mathrm{N}-\mathrm{CH}_{2} \mathrm{CH}_{3}$ ) 19.51; 19.62 (thiazolidinone 5- $\mathrm{CH}_{3}$ ), 32.82; $33.84\left(\mathrm{CH}_{2}\right), 38.36$; 39.17 (thiazolidinone $\left.\mathrm{N}-\mathrm{CH}_{2}\right), 43.24 ; 43.64$ (thiazolidinone 5-CH), 109.08; 109.27 (imidazothiazole $\mathrm{C}_{5}$ ), 110.63; 111.56 (imidazothiazole $\mathrm{C}_{2}$ ), 125.32; $125.35\left(\mathrm{Ph} \mathrm{C}_{2,6}\right), 126.07 ; 127.30$ (imidazothiazole $\mathrm{C}_{3}$ ), 127.73; 127.75 ( $\left.\mathrm{Ph} \mathrm{C}_{4}\right), 129.35 ; 129.37$ ( $\left.\mathrm{Ph} \mathrm{C}_{3,5}\right), 134.87 ; 134.94$ ( $\left.\mathrm{Ph} \mathrm{C}_{1}\right), 146.66 ; 146.74$ (imidazothiazole $\mathrm{C}_{6}$ ), 149.28; 149.34 (imidazothiazole $\mathrm{C}_{7 \mathrm{a}}$ ), 157.16 (thiazolidinone $\mathrm{C}_{2}=\mathrm{N}$ ), 167.32; 169.75 $(\mathrm{CONH}), 174.25 ; 174.75$ (thiazolidinone $\mathrm{C}=\mathrm{O}) .{ }^{13} \mathrm{C}-\mathrm{NMR}$ (DEPT) $(125 \mathrm{MHz}) \delta$ (ppm): 12.81; 13.91 (thiazolidinone $\mathrm{N}-\mathrm{CH}_{2} \mathrm{CH}_{3}$ ), 19.51; 19.62 (thiazolidinone 5- $\mathrm{CH}_{3}$ ), 32.82; $33.83\left(\mathrm{CH}_{2}\right.$ ), 38.36; 39.17 (thiazolidinone $\mathrm{N}-\mathrm{CH}_{2}$ ) 43.24; 43.64 (thiazolidinone 5-CH), 109.08; 109.28 (imidazothiazole $\mathrm{C}_{5}$ ), 110.64; 111.57 (imidazothiazole $\left.\mathrm{C}_{2}\right), \quad 125.32 ; 125.35\left(\mathrm{Ph} \mathrm{C}_{2,6}\right), 127.73 ; 127.75\left(\mathrm{Ph} \mathrm{C}_{4}\right)$ 129.35; 129.37 ( $\left.\mathrm{Ph} \mathrm{C}_{3,5}\right) .{ }^{13} \mathrm{C}-\mathrm{NMR}$ (HSQC) $(125 \mathrm{MHz}) \delta$ (ppm): 12.81; 13.91 (thiazolidinone $\left.\mathrm{N}-\mathrm{CH}_{2} \mathrm{CH}_{3}\right), 19.51 ; 19.62$ (thiazolidinone 5- $\left.\mathrm{CH}_{3}\right), 32.82 ; 33.84\left(\mathrm{CH}_{2}\right), 38.36$; 39.17 (thiazolidinone $\mathrm{N}-\mathrm{CH}_{2}$ ), 43.24; 43.64 (thiazolidinone 5-CH), 109.08; 109.27 (imidazothiazole $\mathrm{C}_{5}$ ), 110.64; 111.57 (imidazothiazole $\mathrm{C}_{2}$ ), 125.32; 125.35 ( $\left.\mathrm{Ph} \mathrm{C}_{2,6}\right)$, 126.07; 127.30 (imidazothiazole $\left.\mathrm{C}_{3}\right), 127.73 ; 127.75\left(\mathrm{Ph} \mathrm{C}_{4}\right)$, 129.35; $129.37\left(\mathrm{Ph} \mathrm{C}_{3,5}\right), 134.87 ; 134.94\left(\mathrm{Ph} \mathrm{C}_{1}\right), 146.66 ; 146.74$ (imidazothiazole $\left.\mathrm{C}_{6}\right), 149.28 ; 149.34$ (imidazothiazole $\mathrm{C}_{7 \mathrm{a}}$ ), 157.16 (thiazolidinone $\mathrm{C}_{2}=\mathrm{N}$ ), 167.32; $169.75(\mathrm{CONH}), 174.25 ; 174.74$ (thiazolidinone 
$\mathrm{C}=\mathrm{O}$ ). Anal. Calcd. for $\mathrm{C}_{19} \mathrm{H}_{19} \mathrm{~N}_{5} \mathrm{O}_{2} \mathrm{~S}_{2}$ : $\mathrm{C}, 55.19 ; \mathrm{H}, 4.63 ; \mathrm{N}, 16.94 ;$ Found: $\mathrm{C}, 55.48 ; \mathrm{H}, 4.65 ; \mathrm{N}, 17.27$. ESI (+) MS: $\mathrm{m} / z[\mathrm{M}+1]^{+} 414(100), 256(6), 214(3), 175(4)$.

\section{3-Propyl-2-[((6-phenylimidazo[2,1-b]thiazol-3-yl)acetyl)hydrazono]-5-methyl-4-thiazolidinone (5)}

UV $\lambda_{\max }(\mathrm{nm}): 199$ (ع 126637), 258 (ع 31808). IR $\mathrm{V}_{\max }\left(\mathrm{cm}^{-1}\right): 3186,3155$ (N-H stretching), 3024 (aromatic CH stretching), 2964, 2933 (C-H stretching), 1716, 1695 (thiazolidinone $\mathrm{C}=\mathrm{O}$ stretching), 1670 (amide I C=O stretching), 1618, $1550(\mathrm{C}=\mathrm{N}, \mathrm{C}=\mathrm{C}$ stretching and amide II, N-H bending vibrations combined with C-N stretching), 1469, 1390 (C-H bending), 1228 (amide III, N-H bending vibrations combined with C-N stretching), 705 (aromatic substitution bending). ${ }^{1} \mathrm{H}-\mathrm{NMR} \delta(\mathrm{ppm}): 0.82\left(\mathrm{t}, 3 \mathrm{H}, \mathrm{J}=7.32 \mathrm{~Hz}\right.$, thiazolidinone $\mathrm{N}^{-} \mathrm{CH}_{2}-\mathrm{CH}_{2-}$ $\left.\mathrm{CH}_{3}\right), 1.52\left(\mathrm{~d}, 3 \mathrm{H}, J=6.83 \mathrm{~Hz}\right.$, thiazolidinone 5- $\left.\mathrm{CHCH}_{3}\right), 1.56-1.64\left(\mathrm{~m}, 2 \mathrm{H}, \mathrm{N}-\mathrm{CH}_{2}-\mathrm{CH}_{2}-\mathrm{CH}_{3}\right), 3.61(\mathrm{t}, 2 \mathrm{H}, J=$ $7.32 \mathrm{~Hz}$, thiazolidinone $\left.\mathrm{N}-\mathrm{CH}_{2}-\mathrm{CH}_{2}-\mathrm{CH}_{3}\right), 3.87$ and $4.08\left(2 \mathrm{~s}, 2 \mathrm{H}, \mathrm{CH}_{2} \mathrm{CO}\right), 4.40(\mathrm{q}, 1 \mathrm{H}, J=7.32 \mathrm{~Hz}$, thiazolidinone 5- $\left.\mathrm{CHCH}_{3}\right), 7.01$ ve $7.05\left(2 \mathrm{~s}, 1 \mathrm{H}\right.$, imidazothiazole $\left.\mathrm{C}_{2}-\mathrm{H}\right), 7.24-7.27\left(\mathrm{~m}, 1 \mathrm{H}, \mathrm{Ph} \mathrm{C}_{4}-\mathrm{H}\right), 7.38$ and 7,40 $\left(2 \mathrm{~d}, 2 \mathrm{H}, J=7.81 ; 7.32 \mathrm{~Hz}, \mathrm{Ph} \mathrm{C}_{3,5}-\mathrm{H}\right), 7.82\left(\mathrm{~d}, 2 \mathrm{H}, J=7.32 \mathrm{~Hz}, \mathrm{Ph} \mathrm{C}_{2,6}-\mathrm{H}\right), 8.14$ and $8.20(2 \mathrm{~s}, 1 \mathrm{H}$, imidazothiazole $\left.\mathrm{C}_{5}-\mathrm{H}\right), 10.52$ and $10.66(2 \mathrm{~s}, 1 \mathrm{H}, \mathrm{CONH})$. Anal. Calcd. for $\mathrm{C}_{20} \mathrm{H}_{21} \mathrm{~N}_{5} \mathrm{O}_{2} \mathrm{~S}_{2}: \mathrm{C}, 56.18 ; \mathrm{H}, 4.95 ; \mathrm{N}, 16.38$; Found: $\mathrm{C}$, $55.95 ; \mathrm{H}, 4.55 ; \mathrm{N}, 16.22$.

\section{3-Allyl-2-[((6-phenylimidazo[2,1-b]thiazol-3-yl)acetyl)hydrazono]-5-methyl-4-thiazolidinone (6)}

UV $\lambda_{\max }(\mathrm{nm}): 199$ (ع 128932), 257 (ع 45530). IR $\mathrm{v}_{\max }\left(\mathrm{cm}^{-1}\right): 3186,3155$ (N-H stretching), 3103 (aromatic C$\mathrm{H}$ stretching), 2987, 2931 (C-H stretching), 1724 (thiazolidinone $\mathrm{C}=\mathrm{O}$ stretching), 1681, 1662 (amide I C=O stretching), 1610, 1558 ( $\mathrm{C}=\mathrm{N}, \mathrm{C}=\mathrm{C}$ stretching and amide II, N-H bending vibrations combined with C-N stretching), 1469, 1381 (C-H bending), 1224 (amide III, N-H bending vibrations combined with C-N stretching), 705 (aromatic substitution bending). ${ }^{1} \mathrm{H}-\mathrm{NMR} \delta(\mathrm{ppm}): 1.53\left(\mathrm{~d}, 3 \mathrm{H}, J=7.14 \mathrm{~Hz}\right.$, thiazolidinone $\left.5-\mathrm{CHCH}_{3}\right), 3.87$ and $4.06\left(2 \mathrm{~s}, 2 \mathrm{H}, \mathrm{CH}_{2} \mathrm{CO}\right), 4.25$ and $4.29\left(2 \mathrm{~d}, 2 \mathrm{H}, J=4.11 ; 5.21 \mathrm{~Hz}, \mathrm{~N}-\mathrm{CH}_{2}-\mathrm{CH}=\mathrm{CH}_{2}\right), 4.45(\mathrm{q}, 1 \mathrm{H}, J=7.13 \mathrm{~Hz}$, thiazolidinone $\left.5-\mathrm{CHCH}_{3}\right), 5.10\left(\mathrm{dd}, 1 \mathrm{H}, J=10.71 \mathrm{~Hz} ; 1.10 \mathrm{~Hz}, \mathrm{~N}-\mathrm{CH}_{2}-\mathrm{CH}=\mathrm{CH}_{2} \mathrm{cis}\right), 5.14(\mathrm{dd}, 1 \mathrm{H}, J=17.29 \mathrm{~Hz}$; $1.10 \mathrm{~Hz}, \mathrm{~N}-\mathrm{CH}_{2}-\mathrm{CH}=\mathrm{CH}_{2}$ trans), 5.78-5.87 (m, $\left.1 \mathrm{H}, \mathrm{N}-\mathrm{CH}_{2}-\mathrm{CH}=\mathrm{CH}_{2}\right), 7.01$ and $7.04\left(2 \mathrm{~s}, 1 \mathrm{H}\right.$, imidazothiazole $\mathrm{C}_{2-}$ $\mathrm{H})$, 7.24-7.27 (m, 1H, Ph $\left.\mathrm{C}_{4}-\mathrm{H}\right), 7.38$ and $7.40\left(2 \mathrm{~d}, 2 \mathrm{H}, J=7.41 ; 7.68 \mathrm{~Hz}, \mathrm{Ph} \mathrm{C}_{3,5}-\mathrm{H}\right), 7.83(\mathrm{~d}, 2 \mathrm{H}, J=8.24 \mathrm{~Hz}, \mathrm{Ph}$ $\left.\mathrm{C}_{2,6}-\mathrm{H}\right), 8.12$ and $8.20\left(2 \mathrm{~s}, 1 \mathrm{H}\right.$, imidazothiazole $\left.\mathrm{C}_{5}-\mathrm{H}\right), 10.66(\mathrm{~s}, 1 \mathrm{H}, \mathrm{CONH})$. Anal. Calcd. for $\mathrm{C}_{20} \mathrm{H}_{19} \mathrm{~N}_{5} \mathrm{O}_{2} \mathrm{~S}_{2}: \mathrm{C}_{\text {, }}$ 56.45; H, 4.50; N, 16.46; Found: C, 56.80; H, 4.56; N, 16.22 .

\section{3-Phenyl-2-[((6-phenylimidazo[2,1-b]thiazol-3-yl)acetyl)hydrazono]-5-methyl-4-thiazolidinone (7)}

UV $\lambda_{\max }(\mathrm{nm}): 199$ (ع 131615), 260 ( $\varepsilon$ 40342). IR $\mathrm{V}_{\max }\left(\mathrm{cm}^{-1}\right): 3441$ (O-H), 3253, 3124 (N-H stretching), 3026 (aromatic C-H stretching), 2980, 2868 (C-H stretching), 1749, 1699 (thiazolidinone C=O stretching), 1643 (amide I C=O stretching), 1589, 1539 ( $\mathrm{C}=\mathrm{N}, \mathrm{C}=\mathrm{C}$ stretching and amide II, $\mathrm{N}-\mathrm{H}$ bending vibrations combined with $\mathrm{C}$ $\mathrm{N}$ stretching), 1467, 1386 (C-H bending), 1269 (amide III, N-H bending vibrations combined with C-N stretching), 819, 736 (aromatic substitution bending). ${ }^{1} \mathrm{H}-\mathrm{NMR} \delta(\mathrm{ppm}): 1.05\left(\mathrm{t}, 3 \mathrm{H}, J=7.32 \mathrm{~Hz}, \mathrm{EtOH}, \mathrm{CH}_{3}\right)$, 1.52 and $1.57\left(2 \mathrm{~d}, 3 \mathrm{H}, J=7.32 ; 7.32 \mathrm{~Hz}\right.$, thiazolidinone $\left.5-\mathrm{CH}_{-} \mathrm{CH}_{3}\right), 3.45\left(\mathrm{q}, 3 \mathrm{H}, J=7.32 \mathrm{~Hz}, \mathrm{EtOH}, \mathrm{CH}_{2}\right), 4.02-$ $4.14\left(\mathrm{~m}, 2 \mathrm{H}, \mathrm{CH}_{2} \mathrm{CO}\right), 4.34(\mathrm{t}, 3 \mathrm{H}, J=5.37 \mathrm{~Hz}, \mathrm{EtOH}, \mathrm{OH}), 4.49$ and $4.53(2 \mathrm{q}, 1 \mathrm{H}, J=7.32 ; 7.32 \mathrm{~Hz}$, thiazolidinone 5- $\left.\mathrm{CHCH}_{3}\right), 6.89\left(\mathrm{~d}, 2 \mathrm{H}, J=7.32 \mathrm{~Hz}\right.$, thiazolidinone 3-Ph $\left.\mathrm{C}_{2,6}-\mathrm{H}\right), 7.14\left(\mathrm{~s}, 1 \mathrm{H}\right.$, imidazothiazole $\left.\mathrm{C}_{2}-\mathrm{H}\right), 7.15-7.27$ $\left(\mathrm{m}, 4 \mathrm{H}\right.$, thiazolidinone $3-\mathrm{Ph} \mathrm{C}_{3,4,5}-\mathrm{H}$ ve $\left.\mathrm{Ph} \mathrm{C}_{4}-\mathrm{H}\right), 7.33$ and $7.35\left(2 \mathrm{~d}, 2 \mathrm{H}, J=7.81 ; 7.32 \mathrm{~Hz}, \mathrm{Ph} \mathrm{C}_{3,5}-\mathrm{H}\right), 7.64$ and $7.66\left(2 \mathrm{~d}, 2 \mathrm{H}, \mathrm{J}=7.32 ; 6.83 \mathrm{~Hz}, \mathrm{Ph} \mathrm{C}_{2,6}-\mathrm{H}\right), 8.08$ and 8.09 (2s, $1 \mathrm{H}$, imidazothiazole $\left.\mathrm{C}_{5}-\mathrm{H}\right), 11.37(\mathrm{~s}, 1 \mathrm{H}, \mathrm{CONH})$. Anal. Calcd. for $\mathrm{C}_{23} \mathrm{H}_{19} \mathrm{~N}_{5} \mathrm{O}_{2} \mathrm{~S}_{2}$. $\mathrm{C}_{2} \mathrm{H}_{5} \mathrm{OH}$ : C, 59.15; H, 4.96; N, 13.80; Found: $\mathrm{C}, 58.91 ; \mathrm{H}, 4.28 ; \mathrm{N}, 13.74$.

\section{3-(4-Methylphenyl)-2-[((6-phenylimidazo[2,1-b]thiazol-3-yl)acetyl)hydrazono]-5-methyl-4-thiazolidinone (8)}

UV $\lambda_{\max }(\mathrm{nm}): 198$ (ع 124654), 262 (ع 52693). IR $\mathrm{v}_{\max }\left(\mathrm{cm}^{-1}\right): 3211,3111$ (N-H stretching), 3022 (aromatic C$\mathrm{H}$ stretching), 2937, 2866 (C-H stretching), 1749, 1705 (thiazolidinone $\mathrm{C}=\mathrm{O}$ stretching), 1643 (amide I C=O stretching), 1604, 1539 ( $\mathrm{C}=\mathrm{N}, \mathrm{C}=\mathrm{C}$ stretching and amide II, N-H bending vibrations combined with C-N stretching), 1469, 1388 (C-H bending), 1273 (amide III, N-H bending vibrations combined with C-N stretching), 823, 725 (aromatic substitution bending). ${ }^{1} \mathrm{H}-\mathrm{NMR} \delta(\mathrm{ppm}): 1.52$ and $1.56(2 \mathrm{~d}, 3 \mathrm{H}, J=7.32 ; 6.84 \mathrm{~Hz}$, thiazolidinone 5-CH-CH $\left.\mathrm{CH}_{3}\right), 2.29\left(\mathrm{~s}, 3 \mathrm{H}\right.$, thiazolidinone 3-Ph 4- $\left.\mathrm{CH}_{3}\right), 4.02-4.13\left(\mathrm{~m}, 2 \mathrm{H}, \mathrm{CH}_{2} \mathrm{CO}\right), 4.48$ and 4.50 $\left(2 \mathrm{q}, 1 \mathrm{H}, J=7.32 ; 7.32 \mathrm{~Hz}\right.$, thiazolidinone $\left.5-\mathrm{CHCH}_{3}\right), 6.79\left(\mathrm{~d}, 2 \mathrm{H}, \mathrm{J}=7.80 \mathrm{~Hz}\right.$, thiazolidinone 3-Ph $\left.\mathrm{C}_{3,5} \mathrm{-H}\right), 7.13$ $\left(\mathrm{s}, 1 \mathrm{H}\right.$, imidazothiazole $\left.\mathrm{C}_{2}-\mathrm{H}\right), 7.14\left(\mathrm{~d}, 1 \mathrm{H}, J=7.81 \mathrm{~Hz}, \mathrm{Ph} \mathrm{C}_{4}-\mathrm{H}\right), 7.19-7.27\left(\mathrm{~m}, 4 \mathrm{H}, \mathrm{Ph} \mathrm{C} \mathrm{C}_{3,5}-\mathrm{H}\right.$ and thiazolidinone 3-Ph $\left.\mathrm{C}_{2,6}-\mathrm{H}\right), 7.64$ and $7.66\left(2 \mathrm{~d}, 2 \mathrm{H}, J=6.35 ; 6.83 \mathrm{~Hz}, \mathrm{Ph} \mathrm{C}_{2,6}-\mathrm{H}\right), 8.08\left(\mathrm{~s}, 1 \mathrm{H}\right.$, imidazothiazole $\left.\mathrm{C}_{5}-\mathrm{H}\right), 11.33$ (s, $1 \mathrm{H}, \mathrm{CONH})$. Anal. Calcd. for $\mathrm{C}_{24} \mathrm{H}_{21} \mathrm{~N}_{5} \mathrm{O}_{2} \mathrm{~S}_{2}: \mathrm{C}, 60.61 ; \mathrm{H}, 4.45 ; \mathrm{N}, 14.73$; Found: $\mathrm{C}, 60.48 ; \mathrm{H}, 4.27 ; \mathrm{N}, 14.42$. 
3-(4-Chlorophenyl)-2-[((6-phenylimidazo[2,1-b]thiazol-3-yl)acetyl)hydrazono]-5-methyl-4-thiazolidinone (9)

UV $\lambda_{\max }(\mathrm{nm}): 202$ ( 2 147459), 262 ( $\left(\right.$ 39855). IR $v_{\max }\left(\mathrm{cm}^{-1}\right): 3230,3107$ (O-H and N-H stretching), 3018 (aromatic C-H stretching), 2980, 2908 (C-H stretching), 1745, 1685 (thiazolidinone C=O stretching), 1654 (amide I C=O stretching), 1600, 1523 ( $\mathrm{C}=\mathrm{N}, \mathrm{C}=\mathrm{C}$ stretching and amide II, N-H bending vibrations combined with $\mathrm{C}$ $\mathrm{N}$ stretching), 1475, 1400 (C-H bending), 1247 (amide III, N-H bending vibrations combined with C-N stretching), 831, 711 (aromatic substitution bending). ${ }^{1} \mathrm{H}-\mathrm{NMR} \delta(\mathrm{ppm}): 1.52$ and $1.57(2 \mathrm{~d}, 3 \mathrm{H}, J=6.84 ; 6.83$ $\mathrm{Hz}$, thiazolidinone 5- $\left.\mathrm{CH}-\mathrm{CH}_{3}\right), 3.97-4.10\left(\mathrm{~m}, 2 \mathrm{H}, \mathrm{CH}_{2} \mathrm{CO}\right), 4.48$ and $4.53(2 \mathrm{q}, 1 \mathrm{H}, J=7.32 ; 7.32 \mathrm{~Hz}$, thiazolidinone $\left.5-\mathrm{CHCH}_{3}\right), 6.90\left(\mathrm{~d}, 2 \mathrm{H}, \mathrm{J}=8.79 \mathrm{~Hz}\right.$, thiazolidinone 3-Ph $\left.\mathrm{C}_{3,5}-\mathrm{H}\right), 7.12\left(\mathrm{~s}, 1 \mathrm{H}\right.$, imidazothiazole $\mathrm{C}_{2-}$ $\mathrm{H})$, 7.19-7.64 (m, 7H, $\mathrm{Ph} \mathrm{C}_{2-6}-\mathrm{H}$ and thiazolidinone 3-Ph $\left.\mathrm{C}_{2,6}-\mathrm{H}\right), 8.10$ and $8.17\left(2 \mathrm{~s}, 1 \mathrm{H}\right.$, imidazothiazole $\left.\mathrm{C}_{5}-\mathrm{H}\right)$, $10.06(\mathrm{~s}, 1 \mathrm{H}, \mathrm{CONH})$. Anal. Calcd. for $\mathrm{C}_{23} \mathrm{H}_{18} \mathrm{ClN}_{5} \mathrm{O}_{2} \mathrm{~S}_{2}$ : C, 53.74; H, 3.92; N, 13.62; Found: C, 53.24; $\mathrm{H}, 3.58 ; \mathrm{N}$, 14.10 .

\section{3-Propyl-2-[((6-(4-chlorophenyl)imidazo[2,1-b]thiazol-3-yl)acetyl)hydrazono]-4-thiazolidinone (10)}

UV $\lambda_{\max }(\mathrm{nm}): 200$ (ع 138598), 258 (ع 93444). IR $\mathrm{v}_{\max }\left(\mathrm{cm}^{-1}\right): 3186,3149$ (N-H stretching), 3028 (aromatic C$\mathrm{H}$ stretching), 2964, 2931 (C-H stretching), 1716 (thiazolidinone $\mathrm{C}=\mathrm{O}$ stretching), 1689, 1666 (amide I C=O stretching), 1616, 1548 ( $\mathrm{C}=\mathrm{N}, \mathrm{C}=\mathrm{C}$ stretching and amide II, N-H bending vibrations combined with C-N stretching), 1462, 1386 (C-H bending), 1234 (amide III, N-H bending vibrations combined with C-N stretching), 1083 (aromatic C-Cl stretching), 846 (aromatic substitution bending). ${ }^{1} \mathrm{H}-\mathrm{NMR} \delta(\mathrm{ppm}): 0.82(\mathrm{t}, 3 \mathrm{H}, J=7.32$ $\mathrm{Hz}$, thiazolidinone $\left.\mathrm{N}-\mathrm{CH}_{2}-\mathrm{CH}_{2}-\mathrm{CH}_{3}\right), 1.49-1.62\left(\mathrm{~m}, 2 \mathrm{H}, \mathrm{N}-\mathrm{CH}_{2}-\mathrm{CH}_{2}-\mathrm{CH}_{3}\right), 3.59(\mathrm{t}, 2 \mathrm{H}, J=7.32 \mathrm{~Hz}$, thiazolidinone $\left.\mathrm{N}-\mathrm{CH}_{2}-\mathrm{CH}_{2}-\mathrm{CH}_{3}\right), 3.82$ and $4.09\left(2 \mathrm{~s}, 2 \mathrm{H}\right.$, thiazolidinone $\left.5-\mathrm{CH}_{2}\right), 3.86$ and $4.07\left(2 \mathrm{~s}, 2 \mathrm{H}, \mathrm{CH}_{2} \mathrm{CO}\right)$, 7.03 and $7.06\left(2 \mathrm{~s}, 1 \mathrm{H}\right.$, imidazothiazole $\left.\mathrm{C}_{2}-\mathrm{H}\right), 7.45\left(\mathrm{~d}, 2 \mathrm{H}, J=8.30 \mathrm{~Hz}, \mathrm{Cl}-\mathrm{Ph} \mathrm{C}_{3,5}-\mathrm{H}\right), 7.81-7.85(\mathrm{~m}, 2 \mathrm{H}, \mathrm{Cl}-\mathrm{Ph}$ $\left.\mathrm{C}_{2,6}-\mathrm{H}\right), 8.20$ ve $8.25\left(2 \mathrm{~s}, 1 \mathrm{H}\right.$, imidazothiazole $\left.\mathrm{C}_{5}-\mathrm{H}\right), 10.52$ and $10.64(2 \mathrm{~s}, 1 \mathrm{H}, \mathrm{CONH})$. Anal. Calcd. for $\mathrm{C}_{19} \mathrm{H}_{18} \mathrm{ClN}_{5} \mathrm{O}_{2} \mathrm{~S}_{2}$ : C, 50.94; H, 4.05; N, 15.63; Found: C, 50.92; H, 3.82; N, 15.48.

\section{3-Methyl-2-[((6-(4-chlorophenyl)imidazo[2,1-b]thiazol-3-yl)acetyl)hydrazono]-5-methyl-4-thiazolidinone (11)}

$\mathrm{UV} \lambda_{\max }(\mathrm{nm}): 200$ (ع 137685), 259 (ع 91342). IR $\mathrm{v}_{\max }\left(\mathrm{cm}^{-1}\right): 3134,3111$ (N-H stretching), 3053 (aromatic C$\mathrm{H}$ stretching), 2980, 2935 (C-H stretching), 1722, 1712 (thiazolidinone $\mathrm{C}=\mathrm{O}$ stretching), 1668 (amide I C=O stretching), 1614, $1556(\mathrm{C}=\mathrm{N}, \mathrm{C}=\mathrm{C}$ stretching and amide II, N-H bending vibrations combined with $\mathrm{C}-\mathrm{N}$ stretching), 1465, 1365 (C-H bending), 1265 (amide III, N-H bending vibrations combined with C-N stretching), 1066 (aromatic C-Cl stretching), 839 (aromatic substitution bending). ${ }^{1} \mathrm{H}-\mathrm{NMR} \delta$ (ppm): 1.52 (d, 3H, $J=7.13$ $\mathrm{Hz}$, thiazolidinone $\left.5-\mathrm{CHCH}_{3}\right), 3.09$ and $3.13\left(2 \mathrm{~s}, 3 \mathrm{H}\right.$, thiazolidinone $\left.\mathrm{N}-\mathrm{CH}_{3}\right), 3.87$ and $4.10\left(2 \mathrm{~s}, 2 \mathrm{H}, \mathrm{CH}_{2} \mathrm{CO}\right)$, $4.38\left(\mathrm{q}, 1 \mathrm{H}, J=7.14 \mathrm{~Hz}\right.$, thiazolidinone $\left.5-\mathrm{CHCH}_{3}\right), 7.06\left(\mathrm{~s}, 1 \mathrm{H}\right.$, imidazothiazole $\left.\mathrm{C}_{2}-\mathrm{H}\right), 7.45(\mathrm{~d}, 2 \mathrm{H}, J=8.51 \mathrm{~Hz}$, Cl-Ph $\left.\mathrm{C}_{3,5} \mathrm{H}\right), 7.83\left(\mathrm{~d}, 2 \mathrm{H}, \mathrm{J}=8.51 \mathrm{~Hz}, \mathrm{Cl}-\mathrm{Ph} \mathrm{C}_{2,6}-\mathrm{H}\right), 8.20$ and $8.24\left(2 \mathrm{~s}, 1 \mathrm{H}\right.$, imidazothiazole $\left.\mathrm{C}_{5}-\mathrm{H}\right), 10.63(\mathrm{~s}, 1 \mathrm{H}$, $\mathrm{CONH}$ ). Anal. Calcd. for $\mathrm{C}_{18} \mathrm{H}_{16} \mathrm{ClN}_{5} \mathrm{O}_{2} \mathrm{~S}_{2}$ : C, 49.82; H, 3.72; N, 16.14; Found: $\mathrm{C}, 50.09 ; \mathrm{H}, 3.85 ; \mathrm{N}, 15.80$.

\section{3-Ethyl-2-[((6-(4-chlorophenyl)imidazo[2,1-b]thiazol-3-yl)acetyl)hydrazono]-5-methyl-4-thiazolidinone (12)}

UV $\lambda_{\max }(\mathrm{nm}): 199$ (ع 132775), 260 (ع 51201). IR $\mathrm{V}_{\max }\left(\mathrm{cm}^{-1}\right): 3180,3151$ (N-H stretching), 3113 (aromatic CH stretching), 2978, 2933 (C-H stretching), 1716 (thiazolidinone C=O stretching), 1691, 1662 (amide I C=O stretching), 1614, $1556(\mathrm{C}=\mathrm{N}, \mathrm{C}=\mathrm{C}$ stretching and amide II, N-H bending vibrations combined with C-N stretching), 1462, 1390 (C-H bending), 1226 (amide III, N-H bending vibrations combined with C-N stretching), 1085 (aromatic $\mathrm{C}-\mathrm{Cl}$ stretching), 846 (aromatic substitution bending). ${ }^{1} \mathrm{H}-\mathrm{NMR} \delta(\mathrm{ppm}): 1.12(\mathrm{t}, 3 \mathrm{H}, J=7.14 \mathrm{~Hz}$, thiazolidinone $\left.\mathrm{N}-\mathrm{CH}_{2}-\mathrm{CH}_{3}\right), 1.51\left(\mathrm{~d}, 3 \mathrm{H}, J=7.14 \mathrm{~Hz}\right.$, thiazolidinone $\left.5-\mathrm{CHCH}_{3}\right), 3.68(\mathrm{q}, 2 \mathrm{H}, J=7.13 \mathrm{~Hz}$, thiazolidinone $\left.\mathrm{N}-\mathrm{CH}_{2}\right), 3.87$ and $4.09\left(2 \mathrm{~s}, 2 \mathrm{H}, \mathrm{CH}_{2} \mathrm{CO}\right), 4.37\left(\mathrm{q}, 1 \mathrm{H}, \mathrm{J}=7.14 \mathrm{~Hz}\right.$, thiazolidinone 5- $\left.\mathrm{CHCH}_{3}\right), 7.04$ and $7.06\left(2 \mathrm{~s}, 1 \mathrm{H}\right.$, imidazothiazole $\left.\mathrm{C}_{2}-\mathrm{H}\right), 7.45\left(\mathrm{~d}, 2 \mathrm{H}, J=8.51 \mathrm{~Hz}, \mathrm{Cl}-\mathrm{Ph} \mathrm{C}_{3,5}-\mathrm{H}\right), 7.84(\mathrm{~d}, 2 \mathrm{H}, J=8.78 \mathrm{~Hz}, \mathrm{Cl}-\mathrm{Ph}$ $\left.\mathrm{C}_{2,6}-\mathrm{H}\right), 8.21$ and $8.25\left(2 \mathrm{~s}, 1 \mathrm{H}\right.$, imidazothiazole $\left.\mathrm{C}_{5}-\mathrm{H}\right), 10.52$ and $10.64(2 \mathrm{~s}, 1 \mathrm{H}, \mathrm{CONH})$. Anal. Calcd. for $\mathrm{C}_{19} \mathrm{H}_{18} \mathrm{ClN}_{5} \mathrm{O}_{2} \mathrm{~S}_{2}$ : C, 50.94; H, 4.05; N, 15.63; Found: C, 51.29; H, 4.19; N, 15.37 .

\section{3-Propyl-2-[((6-(4-chlorophenyl)imidazo[2,1-b]thiazol-3-yl)acetyl)hydrazono]-5-methyl-4-thiazolidinone (13)}

UV $\lambda_{\max }(\mathrm{nm}): 199$ (ع 130740), 260 (ع 33216). IR $\mathrm{v}_{\max }\left(\mathrm{cm}^{-1}\right): 3180,3151$ (N-H stretching), 3080 (aromatic C$\mathrm{H}$ stretching), 2968, 2933 (C-H stretching), 1720 (thiazolidinone $\mathrm{C}=\mathrm{O}$ stretching), 1689, 1666 (amide I C=O stretching), 1614, 1556 ( $\mathrm{C}=\mathrm{N}, \mathrm{C}=\mathrm{C}$ stretching and amide II, N-H bending vibrations combined with C-N stretching), 1465, 1388 (C-H bending), 1230 (amide III, N-H bending vibrations combined with C-N stretching), 1085 (aromatic $\mathrm{C}-\mathrm{Cl}$ stretching), 844 (aromatic substitution bending). ${ }^{1} \mathrm{H}-\mathrm{NMR} \delta$ (ppm): $0.82(\mathrm{t}, 3 \mathrm{H}, J=7.32$ $\mathrm{Hz}$, thiazolidinone $\left.\mathrm{N}-\mathrm{CH}_{2}-\mathrm{CH}_{2}-\mathrm{CH}_{3}\right), 1.52\left(\mathrm{~d}, 3 \mathrm{H}, \mathrm{J}=7.32 \mathrm{~Hz}\right.$, thiazolidinone 5- $\left.\mathrm{CHCH}_{3}\right), 1.54-1.63(\mathrm{~m}, 2 \mathrm{H}$, thiazolidinone $\left.\mathrm{N}-\mathrm{CH}_{2}-\mathrm{CH}_{2}-\mathrm{CH}_{3}\right), 3.61\left(\mathrm{t}, 2 \mathrm{H}, \mathrm{J}=7.32 \mathrm{~Hz}\right.$, thiazolidinone $\left.\mathrm{N}-\mathrm{CH}_{2}-\mathrm{CH}_{2}-\mathrm{CH}_{3}\right), 3.86$ and $4.07(2 \mathrm{~s}$, 
$\left.2 \mathrm{H}, \mathrm{CH}_{2} \mathrm{CO}\right), 4.39\left(\mathrm{q}, 1 \mathrm{H}, \mathrm{J}=7.32 \mathrm{~Hz}\right.$, thiazolidinone $\left.5-\mathrm{CHCH}_{3}\right), 7.03$ and $7.06\left(2 \mathrm{~s}, 1 \mathrm{H}\right.$, imidazothiazole $\left.\mathrm{C}_{2}-\mathrm{H}\right)$, $7.45\left(\mathrm{~d}, 2 \mathrm{H}, J=8.78 \mathrm{~Hz}, \mathrm{Cl}-\mathrm{Ph} \mathrm{C} \mathrm{C}_{3,5}-\mathrm{H}\right), 7.84\left(\mathrm{~d}, 2 \mathrm{H}, J=8.29 \mathrm{~Hz}, \mathrm{Cl}-\mathrm{Ph} \mathrm{C}_{2,6}-\mathrm{H}\right), 8.20$ and $8.25(2 \mathrm{~s}, 1 \mathrm{H}$, imidazothiazole $\left.\mathrm{C}_{5}-\mathrm{H}\right), 10.64(\mathrm{~s}, 1 \mathrm{H}, \mathrm{CONH})$. Anal. Calcd. for $\mathrm{C}_{20} \mathrm{H}_{20} \mathrm{ClN}_{5} \mathrm{O}_{2} \mathrm{~S}_{2}: \mathrm{C}, 52.00 ; \mathrm{H}, 4.36 ; \mathrm{N}, 15.16$; Found: C, 51.72; H, 4.19; N, 14.80 .

\section{3-Phenyl-2-[((6-(4-chlorophenyl)imidazo[2,1-b]thiazol-3-yl)acetyl)hydrazono]-5-methyl-4-thiazolidinone (14)}

UV $\lambda_{\max }(\mathrm{nm}): 201$ (ع 148651), 261 (ع 44491). IR $\mathrm{v}_{\max }\left(\mathrm{cm}^{-1}\right): 3240,3115$ (N-H stretching), 3078 (aromatic C$\mathrm{H}$ stretching), 2978, 2860 (C-H stretching), 1751, 1705 (thiazolidinone $\mathrm{C}=\mathrm{O}$ stretching), 1635 (amide I C=O stretching), 1589, 1537 ( $\mathrm{C}=\mathrm{N}, \mathrm{C}=\mathrm{C}$ stretching and amide II, N-H bending vibrations combined with C-N stretching), 1458, 1392 (C-H bending), 1274 (amide III, N-H bending vibrations combined with C-N stretching), 1089 (aromatic $\mathrm{C}-\mathrm{Cl}$ stretching), 829 (aromatic substitution bending). ${ }^{1} \mathrm{H}-\mathrm{NMR} \delta(\mathrm{ppm}): 1.52$ and 1.57 (2d, $3 \mathrm{H}$, $J=7.32 ; 7.32 \mathrm{~Hz}$, thiazolidinone 5- $\left.\mathrm{CH}-\mathrm{CH}_{3}\right), 4.02-4.14\left(\mathrm{~m}, 2 \mathrm{H}, \mathrm{CH}_{2} \mathrm{CO}\right), 4.48$ and $4.52(2 \mathrm{q}, 1 \mathrm{H}, J=7.32 ; 7.32 \mathrm{~Hz}$, thiazolidinone $\left.5-\mathrm{CHCH}_{3}\right), 6.89\left(\mathrm{~d}, 2 \mathrm{H}, J=7.32 \mathrm{~Hz}\right.$, thiazolidinone 3-Ph $\left.\mathrm{C}_{2,6}-\mathrm{H}\right), 7.14-7.17(\mathrm{~m}, 2 \mathrm{H}$, imidazothiazole $\mathrm{C}_{2}-\mathrm{H}$ and thiazolidinone $\left.3-\mathrm{Ph} \mathrm{C}_{4}-\mathrm{H}\right), 7.28$ and $7.30(2 \mathrm{~d}, 2 \mathrm{H}, J=8.78 ; 8.30 \mathrm{~Hz}$, thiazolidinone 3$\left.\mathrm{Ph} \mathrm{C}_{3,5}-\mathrm{H}\right), 7.33$ and $7.35\left(2 \mathrm{~d}, 2 \mathrm{H}, J=7.33 ; 8.29 \mathrm{~Hz}, \mathrm{Cl}-\mathrm{Ph} \mathrm{C} \mathrm{C}_{3,5}-\mathrm{H}\right), 7.63$ and $7.65(2 \mathrm{~d}, 2 \mathrm{H}, J=8.29 ; 8.79 \mathrm{~Hz}, \mathrm{Cl}-\mathrm{Ph}$ $\left.\mathrm{C}_{2,6}-\mathrm{H}\right), 8.13\left(\mathrm{~s}, 1 \mathrm{H}\right.$, imidazothiazole $\left.\mathrm{C}_{5}-\mathrm{H}\right), 11.36(\mathrm{~s}, 1 \mathrm{H}, \mathrm{CONH}) .{ }^{13} \mathrm{C}-\mathrm{NMR}(\mathrm{APT})(125 \mathrm{MHz}) \delta$ (ppm): 19.69; 19.86 (thiazolidinone 5- $\left.\mathrm{CH}_{3}\right), 33.00 ; 33.05\left(\mathrm{CH}_{2}\right), 40.42 ; 40.48$ (thiazolidinone 5- $\mathrm{CH}$ ), 109.21 (imidazothiazole $\mathrm{C}_{5}$ ), 111.80; 111.85 (imidazothiazole $\mathrm{C}_{2}$ ), $121.44\left(\mathrm{Cl}-\mathrm{Ph} \mathrm{C}_{4}\right), 125.29 ; 125.34$ (thiazolidinone 3-Ph $\mathrm{C}_{2,6}$ ), 126.22; 126.25 (thiazolidinone 3-Ph $\mathrm{C}_{4}$ ), 126.85 (imidazothiazole $\mathrm{C}_{3}$ ), 129.24 (Cl-Ph $\mathrm{C}_{2,6}$ ), 130.13 (thiazolidinone 3-Ph $\left.\mathrm{C}_{3,5}\right), 131.94\left(\mathrm{Cl}-\mathrm{Ph} \mathrm{C} \mathrm{C}_{3,5}\right), 133.64 ; 133.66$ ( $\left.\mathrm{Cl}-\mathrm{Ph} \mathrm{C}_{1}\right), 145.57$ (imidazothiazole $\mathrm{C}_{6}$ ), 148.15; 148.20 (thiazolidinone 3-Ph $\mathrm{C}_{1}$ ), 149.63 (imidazothiazole $\mathrm{C}_{7 \mathrm{a}}$ ), 151.82; 152.10 (thiazolidinone $\mathrm{C}_{2}=\mathrm{N}$ ), 166.35; $166.42(\mathrm{CONH}), 172.47$; 172.62 (thiazolidinone $\mathrm{C}=\mathrm{O}$ ). Anal. Calcd. for $\mathrm{C}_{23} \mathrm{H}_{18} \mathrm{ClN}_{5} \mathrm{O}_{2} \mathrm{~S}_{2}$ : $\mathrm{C}, 55.70 ; \mathrm{H}, 3.66 ; \mathrm{N}, 14.12$; Found: $\mathrm{C}, 56.06 ; \mathrm{H}$, $3.75 ; \mathrm{N}, 13.82$.

\subsection{Biological activity}

\subsubsection{Antiviral activity}

The compounds (1-14) were evaluated for activity against diverse RNA- and DNA-viruses, using the following cell-based assays [45]: (a) Crandell-Rees Feline Kidney (CRFK) cells infected with feline corona virus or feline herpes virus; (b) human embryonic lung (HEL) fibroblast cells infected with herpes simplex virus-1 or -2 , vaccinia virus, vesicular stomatitis virus, an acyclovir-resistant herpes simplex virus-1 strain, or adenovirus-2; (c) human cervixcarcinoma HeLa cells infected with vesicular stomatitis virus, coxsackie B4 virus or respiratory syncytial virus; (d) African green monkey kidney Vero cells infected with para-influenza3 virus, reovirus-1, Sindbis virus, Coxsackie B4 virus or Punta toro virus; (e) Madin-Darby canine kidney (MDCK) cells infected with influenza A/H1N1 subtype (A/PR/8/34 or A/Virginia/ATCC/3/2009), influenza A/H3N2 subtype (A/HK/7/87) or influenza B (B/HK/5/72); and (f) (human T-lymphoblast MT4) cells infected with HIV-1 or HIV-2.

To perform the antiviral assays, the virus was added to subconfluent cell cultures in 96-well plates, and at the same time, the test compounds were added at serial dilutions. Appropriate reference compounds were included, i.e. the virus entry inhibitor dextran sulfate 5000, the broad antiviral agent ribavirin, the antiherpetic drug ganciclovir, and the HIV inhibitor azidothymidine. After 3-6 days incubation at $37{ }^{\circ} \mathrm{C}\left(\right.$ or $35{ }^{\circ} \mathrm{C}$ in the case of influenza virus), the cultures were examined by microscopy to score the compounds' inhibitory effect on virus-induced cytopathic effect (CPE) or their cytotoxicity. For some viruses, antiviral and cytotoxic activities were confirmed by the colorimetric MTS cell viability assay [46].

Acknowledgements: This work was supported by Istanbul University Scientific Research Project (Project Numbers: T-37691, BYP-3076 and BYP-4574). We thank Leentje Persoons and Wim van Dam for dedicated technical assistance.

Author contributions: Concept - N.U.G. Design - N.U.G.; Supervision - N.U.G.; E.P., L.N; Resource - N.U.G.; E.P., L.N.; Materials - N.U.G.; E.P., L.N.; Data Collection \&/or Processing - N.U.G.; E.P., L.N.; Analysis \&/or Interpretation - N.U.G.; E.P., L.N.; Literature Search - N.U.G.; E.P., L.N.; Writing - N.U.G.; E.P., L.N.; Critical Reviews - N.U.G.; E.P., L.N.

Conflict of interest statement: The authors declared no conflict of interest. 


\section{REFERENCES}

[1] Andreani A, Leoni A, Locatelli A, Morigi R, Rambaldi M, Cervellati R, Greco E, Kondratyuk TP, Park EJ, Huang K, Van Breemen RB, Pezzuto JM. Chemopreventive and antioxidant activity of 6-substituted imidazo[2,1- $b]$ thiazoles. Eur J Med Chem. 2013; 68: 412-421.

[2] Ali AR, El-Bendary ER, Ghaly MA, Shehata IA. Synthesis, in vitro anticancer evaluation and in silico studies of novel imidazo[2,1-b]thiazole derivatives bearing pyrazole moieties. Eur J Med Chem. 2014; 75: 492-500.

[3] Budriesi R, Ioan P, Leoni A, Pedemonte N, Locatelli A, Micucci M, Chiarini A, Galietta LJV. Cystic Fibrosis: A new target for 4-imidazo[2,1- $b$ ]thiazole-1,4-dihydropyridines. J Med Chem. 2011; 54(11): 3885-3894.

[4] Ding H, Chen Z, Zhang C, Xin T, Wang Y, Song H, Jiang Y, Chen Y, Xu Y, Tan C. Synthesis and cytotoxic activity of some novel N-pyridinyl-2-(6-phenylimidazo[2,1-b]thiazol-3-yl)acetamide derivatives. Molecules 2012; 17(4): 47034716 .

[5] Park J, El-Gamal MI, Lee YS, Oh C. New imidazo[2,1-b]thiazole derivatives: Synthesis, in vitro anticancer evaluation, and in silico studies. Eur J Med Chem. 2011; 46(12): 5769-5777.

[6] Fidanze SD, Erickson SA, Wang GT, Mantei R, Clark RF, Sorensen BK, Bamaung NY, Kovar P, Johnson EF, Swinger KK, Stewart KD, Zhang Q, Tucker LA, Pappano WN, Wilsbacher JL, Wang J, Sheppard GS, Bell RL, Davidsen SK, Hubbard RD. Imidazo[2,1- $b$ ]thiazoles: Multitargeted inhibitors of both the insulin-like growth factor receptor and members of the epidermal growth factor family of receptor tyrosine kinases. Bioorg Med Chem. 2010; 20(8): 24522455.

[7] Juspin T, Laget M, Terme T, Azas N, Vanelle P. TDAE-assisted synthesis of new imidazo[2,1- $b$ ]thiazole derivatives as anti-infectious agents. Eur J Med Chem. 2010; 45(2);840-845.

[8] Barradas JS, Errea MI, D'Accorso N, Sepúlveda CS, Talarico LB, Damonte EB. Synthesis and antiviral activity of azoles obtained from carbohydrates. Carbohydr Res. 2008; 343(14): 2468-2474.

[9] Mas-Prió J, Torrens-Jover A. Substituted imidazo[2,1-b]thiazole-5-sulfonamide derivatives as 5-HT6 ligands. PCT, World Intellectual Property Organization. 2009; WO 2009/135925 A1.

[10] Aissaoui H, Boss C, Gude M, Koberstein R, Sifferlen T. 3-Aza-bicyclo[3.3.0]octane derivatives as orexin receptors antagonists and their preparation, pharmaceutical compositions and use in the treatment of diseases. PCT, World Intellectual Property Organization. 2009; WO 2009/004584 A1.

[11] Youssef MSK, Ahmed RA, Abbady MS, Abdel-Mohsen SA, Omar AA. Reactions of 4-(2-aminothiazole-4-yl)-3methyl-5-oxo-1-phenyl-2-pyrazoline. Synthesis of thiazolo[3,2- a]pyrimidine and imidazo[2,1- $b$ ] thiazole derivatives. Monatsh Chem. 2008; 139(5): 553-559.

[12] Budriesi R, Ioan P, Locatelli A, Cosconati S, Leoni A, Ugenti MP, Andreani A, Di Toro R, Bedini A, Spampinato S, Marinelli L, Novellino E, Chiarini A. Imidazo[2,1-b]thiazole system: A scaffold endowing dihydropyridines with selective cardiodepressant activity. J Med Chem. 2008; 51(6): 1592-1600.

[13] Barradas JS, Errea MI, D' Accorso NB, Sepúlveda CS, Damonte EB. Imidazo[2,1- $b$ ]thiazole carbohydrate derivatives: Synthesis and antiviral activity against Junin virus, agent of Argentine hemorrhagic fever. Eur J Med Chem. 2011; 46(1): 259-264.

[14] Harding M, Silas B. Preparation of imidazo[2,1-b][1,3]thiazole-5-carboxamide compounds for the treatment of HCV. From PCT Int. Appl. 2013; WO 2013075173 A1 20130530.

[15 Ulusoy N, Çapan G, Ötük G, Kiraz M. Synthesis and antimicrobial activity of new 6b]thiazole derivatives. Boll Chim Farmaceutico 2000; 139(4): 167- 172.

[16] Ulusoy N. Synthesis and antituberculosis activity of cycloalkylidenehydrazide and 4- aza-1-thiaspiro[4.5]decan-3one derivatives of imidazo[2,1-b]thiazole. Arzneim-Forsch/Drug Res. 2002; 52(7): 565-571.

[17] Ulusoy N, Kiraz M, Küçükbasmacı Ö. New 6-(4-Bromophenyl)-imidazo[2,1-b]thiazole derivatives: Synthesis and antimicrobial activity. Monatsh Chem. 2002; 133(10): 1305-1315.

[18] Gürsoy E, Ulusoy Güzeldemirci N. Synthesis and primary cytotoxicity evaluation of new imidazo[2,1-b]thiazole derivatives. Eur J Med Chem. 2007; 42(3): 320-326.

[19] Ulusoy Güzeldemirci N, Küçükbasmacı Ö. Synthesis and antimicrobial activity evaluation of new 1,2,4-triazoles and 1,3,4-thiadiazoles bearing imidazo[2,1-b]thiazole moiety. Eur J Med Chem. 2010; 45(1): 63-68. 
[20] Ulusoy Güzeldemirci N, Şatana D, Küçükbasmacı Ö. Synthesis, characterization, and antimicrobial evaluation of some new hydrazinecarbothioamide, 1,2,4-triazole and 1,3,4-thiadiazole derivatives. J Enzym Inhib Med Chem. 2013; 28(5): 968-973.

[21] Masoud GN, Youssef AM, Khalek MMA, Wahab AEA, Labouta IM, Hazzaa AAB. Design, synthesis, and biological evaluation of new 4-thiazolidinone derivatives substituted with benzimidazole ring as potential chemotherapeutic agents. Med Chem Res. 2013; 22(2): 707-725.

[22] Nandagokula C, Poojary B, Vittal S, Shenoy S, Shetty P, Tangavelu A. Synthesis, characterization, and biological evaluation of some $\mathrm{N}$-aryl hydrazones and their 2,3-disubstituted-4-thiazolidinone derivatives. Med Chem Res. 2013; 22(1): 253-266.

[23] Sarkanj B, Molnar M, Cacic M, Gille L. 4-Methyl-7-hydroxycoumarinantifungal and antioxidant activity enhancement by substitution with thiosemicarbazide and thiazolidinone moieties. Food Chem. 2013; 139(1): 488-495.

[24] Raza S, Srivastava SP, Srivastava DS, Srivastava AK, Haq W, Katti SB. Thiazolidin-4-one and thiazinan-4-one derivatives analogous to rosiglitazone as potential antihyperglycemic and antidyslipidemic agents. Eur J Med Chem. 2013; 63: 611-620.

[25] Parmar SS, Dwivedi C, Chaudhari A, Gupta TK. Substituted thiazolidones and their selective inhibition of nicotinamide-adenin dinucleotide depented oxidations. J Med Chem. 1972; 15(1): 99-101.

[26] Joshi P, Anderson C, Binch H, Hadida S, Yoo S, Bergeron D, Decker C, Terhaar E, Moore J, Garcia-Guzman M, Termin A. Identification of potent CNS-penetrant thiazolidinones as novel CGRP receptor antagonists. Bioorg Med Chem Lett. 2014; 24(3): 845-849.

[27] Bhalgat CM, Darda PV, Bothara KG, Bhandari SV, Gandhi J, Ramesh B. Synthesis and pharmacological screening of some novel antihypertensive agents possessing 5-benzylidene-2-(phenylimino)-thiazolidin-4-one ring. Eur J Med Chem. 2014; 76: 580-588.

[28] Jain AK, Vaidya A, Ravichandran V, Kashaw SK. Recent developments and biological activities of thiazolidinone derivatives: A review. Bioorg Med Chem. 2012; 20(11): 3378-3395.

[29] Rawal RK, Prabhakar YS, Katti SB, De Clercq E. 2-(Aryl)-3-furan-2-ylmethyl-thiazolidin-4-ones as selective HIV-RT inhibitors. Bioorg Med Chem. 2005; 13(24): 6771-6776.

[30] Verma A, Saraf SK. 4-Thiazolidinone-A biologically active scaffold. Eur J Med Chem. 2008; 43(5): 897-905.

[31] Küçükgüzel İ, Satılmış G, Gurukumar KR, Basu A, Tatar E, Nichols DB, Talele TT, Kaushik-Basu N. 2Heteroarylimino-5-arylidene-4-thiazolidinones as a new class of non-nucleoside inhibitors of HCV NS5B polymerase. Eur J Med Chem. 2013; 69: 931-941.

[32] Havrylyuk D, Zimenkovsky B, Vasylenko O, Day CW, Smee DF, Grellier P, Lesyk R. Synthesis and biological activity evaluation of 5-pyrazoline substituted 4-thiazolidinones. Eur J Med Chem. 2013; 66: 228-237.

[33] Barreca ML, Chimirri A, Luca LDe, Monforte AM, Monforte P, Rao A, Zappala M, Balzarini J, Clercq Ede, Pannecouque C, Witvrouw M. Discovery of 2,3-diaryl-1,3-thiazolidin-4-ones as potent anti-HIV-1 agents. Bioorg Med Chem Lett 2001; 11(13): 1793-1796.

[34] Tripathi AC, Gupta SJ, Fatima GN, Sonar PK, Verma A. 4-Thiazolidinones: The advances continue... Eur J Med Chem. 2014; 72: 52-77.

[35] Arnold E, Das K, Ding J, Yadav PN, Hsiou Y, Boyer PI, Hughes SH. Targeting HIV reverse transcriptase for antiAIDS drug design: Structural and biological considerations for chemotherapeutic strategies. Drug Des Discov. 1996; 13(3-4): 29-47.

[36] Gazzard B, Moyle G. and on behalf of the BHIVA Guidelines Writing Committee. 1998 revision to the British HIV Association guidelines for antiretroviral treatment of HIV seropositive individuals. Lancet 1998; 352(9124): 314-316.

[37] Čačić M, Molnar M, Šarkanj B, Has-Schön E, Rajković V. Synthesis and antioxidant activity of some new coumarinyl1,3-thiazolidine-4-ones. Molecules 2010; 15(10): 6795-6809.

[38] Özkırımlı S, Kazan F, Tunalı Y. Synthesis, antibacterial and antifungal activities of 3-(1,2,4-triazol-3-il)-4thiazolidinones. J Enzym Inhib Med Chem. 2009; 24(2): 447-452.

[39] Robert JF, Xicluna A, Panouse JJ. Advances in heterocyclic chemistry. Eur J Med Chem Chim Ther. $1975 ; 10: 59-64$.

[40] Cesur N, Cesur Z, Güner H, Kasımoğulları Ö. Fused Heterocycles: Synthesis of some new imidazothiazoles. Heterocycl Com. 2002; 8(5): 433-438. 
[41] Kuhmstedt H, Kottke K, Knoke D, Robert JF, Panouse JJ. Synthesis of amides and heterocyclic acylhydrazides with potential immunomodulator properties. Ann Pharm Fr. 1982; 40: 425-429.

[42] Krečmerová M, Holý A, Pohl R, Masojidková M, Andrei G, Naesens L, Neyts J, Balzarini J, De Clercq E, Snoeck R. Ester Prodrugs of cyclic 1-(S)-[3-Hydroxy-2-(phosphonomethoxy)propyl]-5-azacytosine: synthesis and antiviral activity. J Med Chem. 2007; 50(23): 5765-5772.

[43] Harraga S, Nicod L, Drouhin JP, Xicluna A, Panouse JJ, Seilles E, Robert JF. Imidazo[2,1-b]thiazole derivatives. XI. Modulation of the CD2-receptor of human T trypsinized lymphocytes by several imidazo[2,1- $b$ ]thiazoles. Eur J Med Chem. 1994; 29(4): 309-315.

[44] Ulusoy N, Çapan G, Ergenç N, Ötük Sanış G, Kiraz M, Kaya D. Synthesis and antimicrobial activity of novel imidazo[2,1-b]thiazolylacetylamino/hydrazono 4-thiazolidinones. Acta Pharm Turc 1997(4); 39: 181-186.

[45] Çapan G, Ulusoy N, Ergenç N, Kiraz M. New 6-phenylimidazo[2,1-b]thiazole derivatives: Synthesis and antifungal activity. Monatsh Chem. 1999; 130(11): 1399-1407.

[46] Vanderlinden E, Göktas F, Cesur Z, Froeyen M, Reed ML, Russell CJ, Cesur N, Naesens L, Novel inhibitors of Influenza virus fusion: Structure-activity relationship and interaction with the viral hemagglutinin. J Virol. 2010; 84(9): 4277-4288. 